\title{
ESPECTADORES Y LECTORAS: REPRESENTACIONES E INFLUENCIA DEL PÚBLICO FEMENINO EN LA PRENSA DEL SIGLO XVIII ${ }^{1}$
}

\author{
Mónica BOLLIFER PERLGA
}

"Amados señores y hermanos míos: El Diario es un papel cuyo principal objeto es facilitar al Público, quantas cosas de mecanismo, víveres, y servicio común bay [...]; es también el Diario un papel que puede servir de pasto a la sociedad, escusando la murnuración, y las conversaciones de cosas inútiles [...] Si todos los quie deben a Dios talento e instrucción la facilitasen. sería utilísimo, y el Diario un papel muy interesante: yo, por muger, carezco de todos principios para substituirme a los literatos, me consumo de este zelo doméstico o social por ver que los hombres nos han privado de las letras para tenerlas en inacción [...]: ruego a los sensatos se unan a subministrar al Público motivos de instrucción, y de diversión en los Diarios, [...] y si así no lo quisieren hacer, les ofrezeo unir algunas socias de mi sexo, que hagan lo que Vmds. no pueden hacer, o 10 quieren.

... «Alguna vez había de llegar la ocasión, en que se viesen Catones sin barbas, y Licurgos eon basquiñas: no ha de estar siempre ceñido el don de consejo á las pelucas, ni han de hacer sudar las prensas los sombreros [...] No, señores mios; hoy quiero, deponiendo el encogimiento propio de mi sexo, dar leyes, corregir ahusos, reprehender ridiculezes, y pensar como Vms. piensan; pues amyue atropelle nuestra antigua condición, que es la de siempre ser hypocritas de pensamientos, los he de echar á volar, para que vea el

Este trabujo se inscribe en el marco del proyecto de investigación La construcción de la sociedad moderna en España (1750-1845). Transformaciones y cambios de significudo en el espacio y ámbito de los esitos de vida. 1)GI(YYT PB93-0686. 
mundo á una muger que picnsa con teflexior, corrige ron pundencia, anulesta con madurez, y critica con chistes?"

Una anónima adama de esta ciudad», con las iniciales C.F.D., y «Beatriz Cienfuegos». Una lectora del Diario de Valencin que remite a está publicación sus quejas y sugerencias y una escritora que se presenta a su público al iniciar sa periódico La Pensadora Gaditana. Dos ejemplos entre la multitud de firmas femeninas que pululan en los papeles periódicos del siglo XVIII. Pero, ¿realmente son tales? ¿No se ha sospechado desde su propia época, y así han tendido a admitirlo los estudiosus, que bajo el nombre de «Beatriz Cienfuegos» se neultala un enlesístico? Igualmente posible es que la anónima dama valenciana no fuese sino uno de los disfraces con que solían cubrirse los periodistas, hombres de los mil nombres que con frecuencia firmaban sus colaboraciones con pseudónimos o iniciales y que eran procilives en el siglo XVIII a practicar el travestismo literario, vistiendo ante su público ropas femeninas. En cualquier caso, fuesen mujeres reales o bien personajes fícticios on el perpetuo baile de dislraces que se desanollaba en las páginas de la prensa, una y otra constituyen muestras bien representativas de un fenómeno propio de la produeción poriodística, española y europea, del siglo XVIIL: la fresuente presencia de las mujeres en sus páginas, on un doble sentido; como público potencial al que los periodistas huscaban y trataban de complacer a la vez que de modelar, y como lectoras que participaban con sus cartas o escritoras que daban a conocer en este medio sus creaciones literarias. Asi era porque los periorlistas, en tanto que hombres de su tiempo que se cnvanccían de su condición de reformadores de la sociedad a través de la palabra escrita, compartían la obsesión ilustrada por construir un nuevo modelo de mujer discreta, doméstica y sensible, levemente instruida pero no sabia?. Una mujer que supicse salisfacer las exigencias de unos

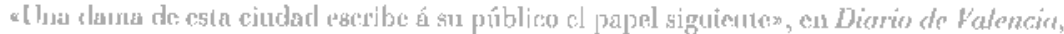

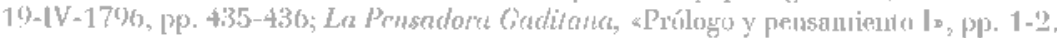

Lil beabo de yue la reforma de las costumbures femeninas constinya un tema cerntral en la

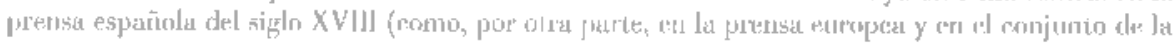

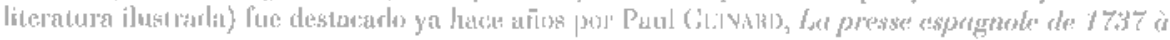
1791. Fommation of signifietion d'un geme. Paris, Cente de Recherches I lispaniques, 197:3, pp.

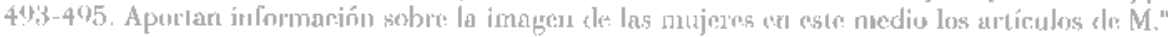

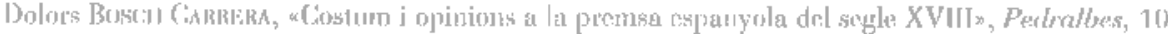

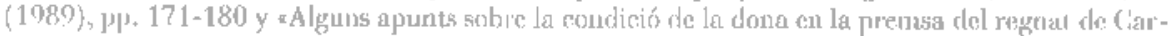

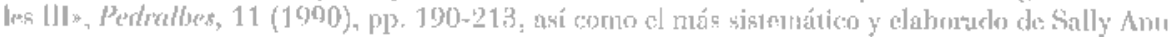

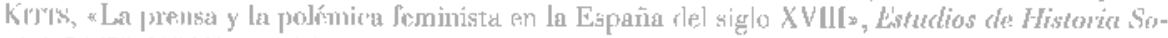
cial, $51 / 52(1900)$, pp. 265-274. Aurvque con un enfoque interpretativo bastante diferente de los adophados por estos pstudios, lá jyenso ha constituido una fuente esencial de nuesura investigraión

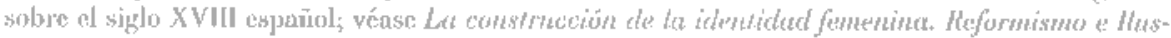
trercion, tesis doctoral inédita, Universidat de Valencia, 1095 
deberes domésticos que se redefinían como absorbentes y primordiales, educando a sus hijos en los principios ilustrados y creando para el esposo un entorno agradable, pero que también pudiese cumplir con los requerimientos de la conversación y la sociabilidad de su tiempo. A la vez, como escritores quo dependían del favor del público para el éxito de sus publicaciones, los hombres de la prensa competían por captar el mercado que suponían las lectoras.

Tal como ha venido destacando la historiografía, la prensa periódica consiituía el instrumento de comunicación cultural por excelencia de la Ilustración. Era una tribuna pública caracterizada por la amplitud de su audiencia, que sobrepasaba los círculos eruditos para alcanzar a un público amplio, por su periodicidad y por las posibilidades de divulgación que permitíat. Entre sus autores se fue abriendo paso poco a poco a lo largo del siglo la figura del escritor profesional, que no dependía de ningúm mecenas sino de la acogida que sus escritos tuviesen entre los lectores, lo que le sometía a las preferencias de éstos o, más precisamente, a la imagen que de ellas se forjaba el periodista.5 Por ello, la relación que cstablecía un diarista con su público resultaba mucho más estrecha e iumediata que la que vinculaba a autor y lector eus otros géneros literarios. Otorgaba a los lectores la posibilidad de influir en la opinión pública, contestando al redactor o a otros lectores en las páginas de la publicación't. Los periodistas, a su vez, contaban con un poderoso medio de modelar las opiniones de quienes le seguían con regularidad. Adoptando recursos de captación o

+ Sobre la prensa española del siglo XVIII son fundamentales, descle una perspectiva general, el estudio clásico y ya citado de Gininard, asi como las síntesis de Luis Miguel Eveiso Rlacio, "Prensa y opinión públicas en La époce de tos primeros Borbunes. I. Lat cultura entre el Burroco y Lu Ihustración (1680-1759). Thistoria de España. XXIX, Madrid, Espasa Calpe, 1985, y «Prensa y

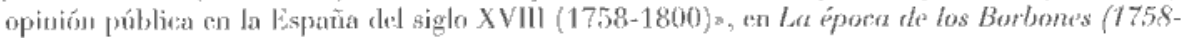
1508). El Estado y le rullura. Historiat de Espeña. XXXI, Marlrid, Espasa Calpe, 1987 y la de M."

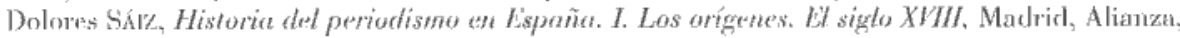
1983. El congreso sobre Pertodismo ellustración en Espeñu, chyas actas han sielo publicadas en un

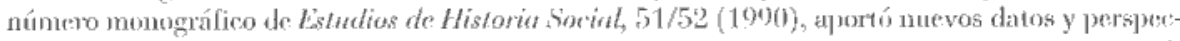

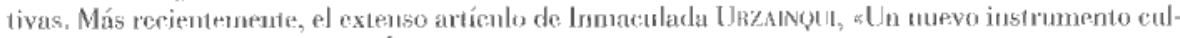

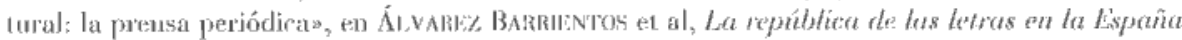
del siglo X'III, Mardricl, CSIC; 1995, pp. 125-215, presta una atención particular ul significado de la prensá como insirumento culural y a la nueva relación que establecía con el público lector.

a Jes Iccteurs, on tout au moins l'inagt: que s'en faisai l'éditcur in l'tuenşaient probablement le conteru du périorlique tout vomme le contenu du périodique dilfusait une influence extérieur par

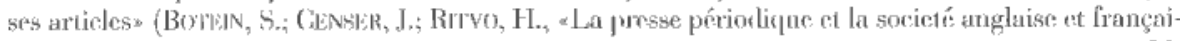
se au XVIIIe siède: una approshe comparative*, en Revue d histoire moderne el contemporrume, 32 , 1085, pp. 209-236; cita p. 213).

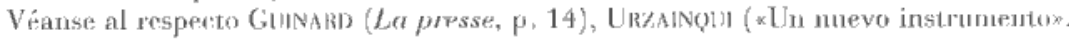

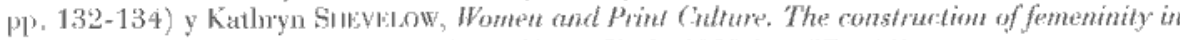
the earty periodical, Routledge, Londres y Nueva York, 1989) (pl. 37 y 44). 
estrategias de construcéón del público ("audience-budiding strutegécs»), buscaba de modo activo la adhesión de los lectores y lectoras, créndoles necesidades, estableciendo con ellos una relación de confianza y suscitando su participación. Mediante estos mecanismos, los invitaban a integrarse en una acomunidad de lectores» a la que suponían una identidad culural compartida? Interpelar en segunda persona al público y representar en el texto al lector y la lectora imaginarios cumplín esa función. creando una «complicidad» entre autores y público que difuminaba los límites entre lectura y escritura, entre texto y realidad. Así, los puriodistas del sigło XVIII aludian con freauenciza a la rocepeión que sus obras tenían entre los lectores, les solicitaban que remitiesen sus cartas, críticas y colaboraciones, entablaban diálogos con ellos o bien reproducían las discusiones que había suscitado la aparición de algún artículo".

Entre este público al que se representaba interesado y participante, dispuesto a expresar sus opiniones o a hacer sus confidencias en ell foro público de la prensa, ocupaban un lugar destacado las mujeres, como la señora que en las

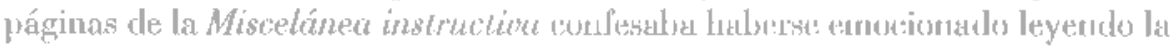
Clarisa Harlowe de Richardson". De hecho, interpelar a las lectoras constituyó en torla Europa prácticanente una cláubula de estilo propia (aurque no exclusiva) de las revistas de tipo «espectador». Ya a finales del siglo XVII las Nenvelles de la Réproblique des Lettres de Pierre Bayle o el Mercure galont buscaba la aprobación de un hipotético público femenino, 1endencia que consolidaron los

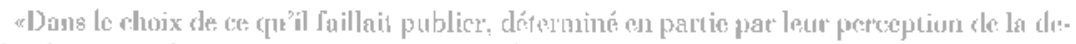
mande, Ires divertenurs de journaux du XVIIIò siècle fournitent des articles qui peuvent avoir couso-

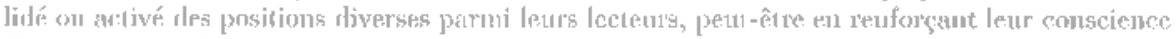

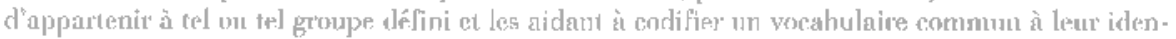

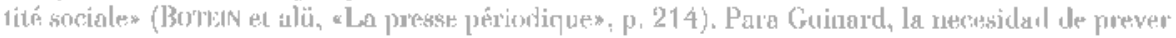

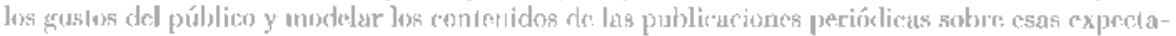

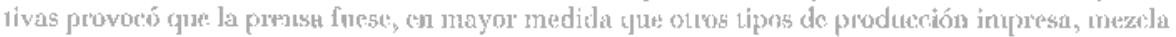
de la expresión de la mentalidad de los editores y del modo en que éstos se vepresseutaban la men-

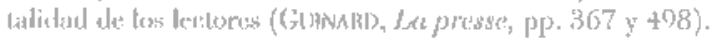

" Esir es nu fenómeno que han subrayacto los estudios sobre la prensa en el siglo XVIII, en

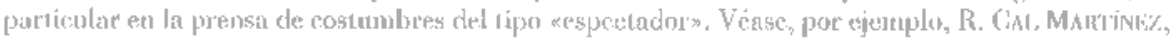

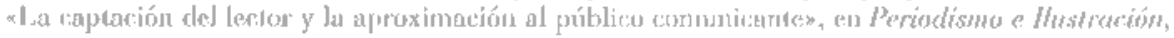

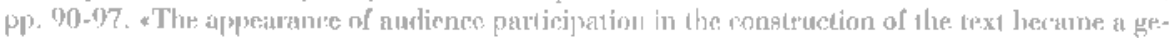

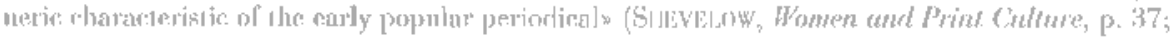

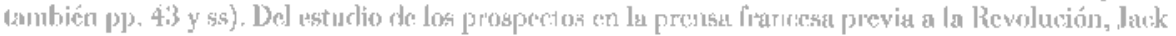

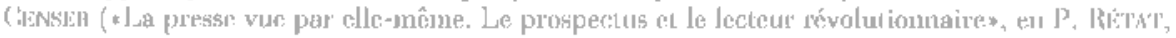

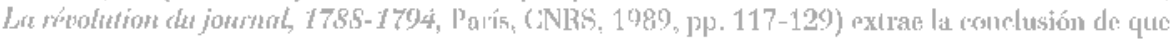

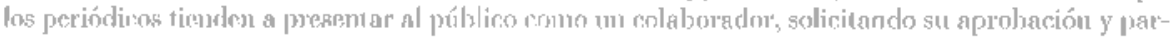

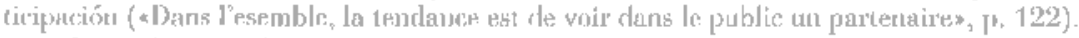

La lectora a la que se latría referencia en el n." 17 (t. VI) de la Miscélónea instructimer, o

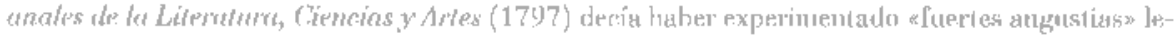
yendo esa novela, apor haber navido viva y sensible ( 1,183 ). 
«espectadores» franceses ${ }^{10}$. En Inglaterra, fue rasgo característico de los «essayperiodical», desde el Athenian Mercury de finales del XVII hasta el Visiter o el Free Thinker, pasando por los colebérrimos The Spectator y The Tatler, como lo fuc en Alemania en las que allí se llamaban Moralische Wochenschriften". En estas y en otras publicaciones las lectoras aparecían de múltiples formas. Los periodistas trataban de recabar su favor, en los prospectos iniciales o a lo largo de las páginas de sus periódicos, presentándolas como un grupo especialmente necesitado de los consejos, instrucción y entretenimiento que sus publicaciones podían proporcionar. Se referían con complacencia a la aceptación que ellas les dispensaban, real o ficticia, pero en cualquier caso susceptible de provocar un efecto de arrastre. Insertaban en sus publicaciones cartas o colaboraciones de supuestas lectoras, personajes que en alguna ocasión llegaban a adquirir una corporeidad ficticia, prolongando durante un tiempo su presencia como colaboradoras del periódico, como «Jenny Distaff» en el Tatler inglés o "D." Leonor» en el Diaro de Valenciu. Por último, los diaristas adoptaban con frecuencia pscudónimos femeninos para encabezar artículos y cartas, e incluso a veces toda una publicación. Con el tiempo, y dentro del proceso general de progresiva especialización de la prensa periódica, esta atención dedicada a las lectorals condujo en muchos países a la aparición de publicaciones que se dirigían espećlicamente a un mercado femenino. Este fenómeno había de tener implicaciones ambiguas: por una parte, es posible que estimulase a las mujeres a leer y escribir, pero, por otra, restringió y delimitó los tenas que se consideraban propios de cllas, dando lugar a uná "prensa femenina" que se ocupaba fundamentalmente de modas y labores domésticas, de educación y moral. En Lspaña este tipo de periódicos no alcanzó a desarrollarse en el signlo XVIII, y por ello resulta paradójica la atención que los diaristas dedicaban a un hipótecico público femenino, representando como activo y participante, frente a la realidad de $u$ mercado lector todavía restringido. Aunque es cierto que la prensa española imi-

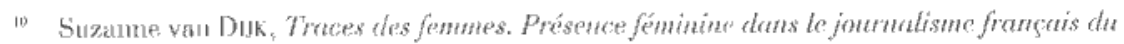
XFlleme siéte, Ansterdian, Holland University Press, 1988 (p). 9-10); en p. 21 comenta la presemcia consiante de figuras fomeninas en pste grenero: a Elles y figurent comme sujets des discours, comme personnages dons les nurvations et comme signatairs de letues supposéco de lectrices"; ver

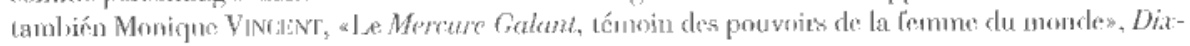
septime siecle, $36(1984), \mathrm{pl}, 241-242$.

$"$ Sobre estos feurmenos en la preusa alenuana, véase Siliaron Mariè di Fino, The Intellec-

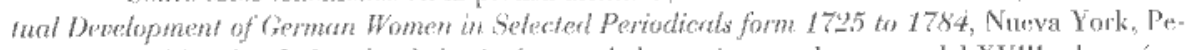
ter Lang, 1900; sobre Iralia, foude las imágenes de las mujeres en la prensa del XVIll y los orige-

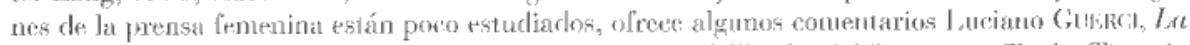

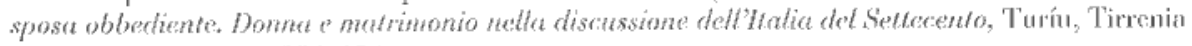
stampatori, 1988, pp. 233-234. 
taba géneros periodisticos extranjeros aut incoruoraban esta deferencia entre sus rasgos de estilo, no parece que la recurrente presencia litcraria de las lectoras pueda despacharse como un mero mimetismo literario que imponía fórmulas de relación cortés con un público inexistente, sino que debe analizarse como nua imagen que traducía las expectativas de los periodistas y a la vez expresaba, en positivo o en negativo, la idea que éstos albergaban de la lectora modélica.

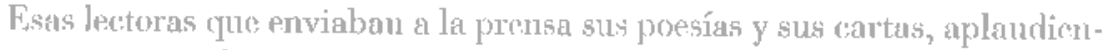
do las opiniones defendidas en los periódicos o quejándose por ellas, que discudian "ntre sí y con otros lectores, jeran mujeres reales o personajes fictions ereados por los periodistas? Algumas de las cartas revelan l'ácilmente su carácter apócrifo, otras parecen ser auténicas y la mayoría dejan espacio a la duda. Por Allo, tan inadecuado resulta tomarlos cono testimonio verídico de las reaccioJes de las lectoras, domo menospreciar el siguificado que tienen en las representaciones y las prácticas de la lectura y la escritura. Parecc mecesario dejar de plantearse como prioritaria la cuestión, en última instancia irresoluble, de la "autenicidad» de las cartas y analizar esas figuras de lectoras comno imágenes que actuaban de forma compleja, creando una esperial rolatión entre las lectoras y los periodistas ${ }^{t 2}$. Verdaderas o no, al crear una apariencia de participación del público producían un "efecto de realidad» susceptible de promover la identificación de las lectoras con los mensajes que transmitía el periódico y quizá estimulasen en algunas de ellas deseos de darse a conocer en público, pasando de la lectura a la escriura y participando efectivamente en el intercambio de opiniones. De ese modo, los periodistas participaban, a su manera, de lá voluntad ilustrada de disciplinar a las mujeres acomodadas, representaudo en tintes negativos las prácticas sociales y culturales que decían propias de las élites: el cortejo, la sociabilidad mundana, la preoedpación por las apariencias, e imponiéndoles nuevos valores y nomnas de conducka. Y lo lacían con los recursos que

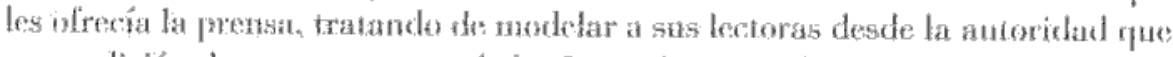
su comdición de representantes de las Lueses les otorguba a ojes de su publico y desde la facilidad de penetración que les permilian sus textos breves próó dicos, sencillos y amenos. El modo que interpelaban a las lectoras y las hacían aparecer en sus publicaciones formaba parte de este ejercisio persuasivo.

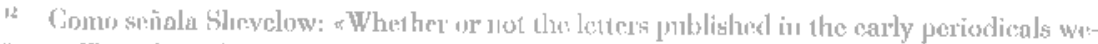
re by "adual" readers, they were represented as the work of the perisdical's readership: the ajpe-

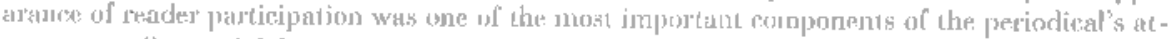

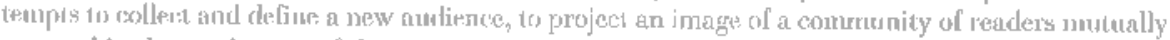

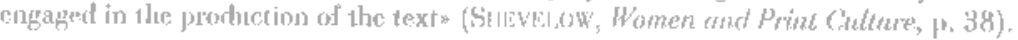


que guardaba una doble relación con el desarrollo de un público de lectoras reales y con la relativa floración de escritoras que tuvo lugar en la segunda mitad del siglo XVIII. Respondía a esos cambios y al mismo tiempo los propiciaba, contribuyendo a fomentar la intervención de las lectoras y disminuyendo la percepción de excepcionalidad que acompañaba tradicionalmente a la escritura femenina, a la vez que delimitaba los modos en que una y otra debían producirse. Los disfraces femeninos permitían imponer a las lectoras pautas de conducta por un medio más sutil y tal vez más efectivo de lo que resultaban las diatribas o los preceptos de otros textos más claramente aleccionadores. Pero al mismo tiempo la pluralidad de voces que se dejaban oir en los periódicos, concordantes o discordantes, representadas en tonos positivos o negativos, dejaba abiertas amplias posibilidades de lectura. A los ojos del público de ambos sexos las intervenciones de las alectoras podían interpretarse en términos que legitimaban el ejercicio de la escritura por parte de las mujeres 0 , por el contrario, banalizarse leyéndolas en clave irónjea; podían servir para demostrar las capacidades intelectuales de las mujeres y apoyar sus críticas a las normas sociales de relación entre los sexos, o bien para ridiculizar tales pretensiones. Semiocultos tras esos ropajes, los periodistas podían permitirse jugar con el contraste y la paradoja, sabrosos ingredientes para atraerse el interés del público, a la vez que mantenían cierta ambigüedad sobre sus verdaderas intenciones.

\section{Los pensadores piensan a las mujeres}

La aparición en el panorama pcriodístico español del siglo XVIII de una prensa de costumbres según el modelo conocido como aespectador» proporcionó nuevas pautas y recursos en la relación entre la voz del autor y las lectoras. Ciaracterizadas por ensamblar discursos morales y cartas en torno a la figura literaria de un "pensador», "observador", "hablador» o *censor» que decía contemplar, juzgar e intentar reformar los comportamientos sociales, estas publicaciones, de las que el primer ejemplo fue el Duende especulativo (1761) y los más brillantes El Pensador de Clavijo y Fajardo (1763) y El Censor de Pereira y García del Cañuelo (1781-1787), entablaban con su público una relación estrecha. Un vínculo tejido de consejos y de polémicas, de mutuas alabanzas y reconvenciones, que pretendía cambiar las conductas no a través del tono impersonal de las lecciones morales, sino fingiendo ante los lectores que los personajes que contaban sus experiencias, daban sus opiniones o solicitaban la del aespectador» eran personas reales, e induciéndoles, de ese modo, a confiar en los consejos de esa figura a veces burlona y otras didáctica. 
Los primeros «espectadores" españoles initaron de sus modelos turopeos, entre otros rasgos, la deferencia hacia el público femenino. No eran los primeros en hacerlo. Incluso en el tradicional y misógino Caxón de sastre (17601761), un hombre tán consciente de la imperiosa necesidad que el periodista profesional tenía de propiciarse un público amplio como Nifo trató de ganarse el favor de las nujeres, argumentando que cran ellas las que más precisaban de lecturas para formar la sensibilidad y el entendimiento:

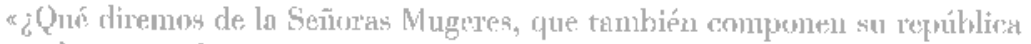
ch el assuno de que se trata? Apenss se hallará uná que (o por sonsiderar imnítil rel testudie jara su estado, pn que conzmnente se comete un notable despropósito, opor las domésticas orupacinnes de que se ve cercado su destino) no responda, y sin que se le pueda ocupur fundadá réplica, que al [sic] leè todo un Trataclo, o Libro (exceptuando Comcdias, o Historias annorosas) no c.s para el comum Pueblo de su sexo, ni aum para las que infectan annor a las Ciencias, por hacer mas amena su conversación, y mus poderoso el imperio de la liermosura, añadiendo, que no todos los Libros son convenientes ni láciles para su vaga, y mudable reflexión [...] A mí me parece (y creen spue no me erugaino) que las Señoras mugeres purden ocupdra algunos ratos, de los mu-

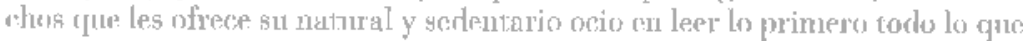
conduce al govierno del corazón, y después foldas las galanterín del discurso, que gnardes mas conformidar, y perentesco con la modestia, e inviolables leyes de su pstados (pp. XXXVII-XXXVII).

Ni qué decir tiene que esa necesidad de lecturas «convenientes» que pretendía crearles habia de ser colmada por sus escritos. Por cllo, aunque muchos do ellos dejasen entrever una gran desconfianza hacia las capacidades morales e intelectuales de las mujeres, cuidó de hacer aprarecer en el n." 50 (t. VI) de su Caxón de sastre a una dama que representaba la reacción adversa de las lectoras a los textos misóginos que había reproducido en números anteriores, y la tomó como pretexto para hacer una defenan, tradicionalista y retórica, de las mujeres ${ }^{13}$.

fiueron, no obstante, los espectadores los que convirtieron la referencia al público femenino prácticamente en una cláusula de estilo. La "personalización» de la voz del narrador que caracterizaba a estos periódicos dotaba a la relación entre éste y su público de una dimensión sexuada: hablando on tanto que hombre, el «cspectador», "que snlía dirigirse a sus lectores con una mezela de complacencia, complicidad y autoridad, al interpelar a las lectoras tendía a adoptar, como observa Kathryn Shevelow en el caso inglés, una postura protectora y casi patermalista, mostrándose ora próximo, ora distante al alternar el tratamiento en segunda y tercera persona, según anrecia Suzanne van Dijk

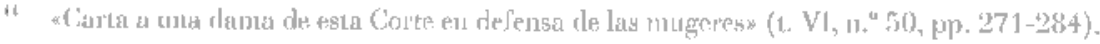


en uno de los primeros aespectadoress en lengua francesa, Le Misantrope de Justus van Effen ${ }^{1+}$. El más célebre de los espectadores» españoles, el Pensador de (lavijo y lajardo, entabló también con sus supuestas lectoras una relación entre complaciente y severa. Tras darse a conocer, como mandaban los cánones del género, en el primer número, el pensamiento II manifestaba su deseo de captar la atención y la benevolencia del público femenino, al que apelaba en tono galante, por mucho que negase propósitos aduladores, y al que apcnas insinuaba la conveniencia de reformar ciertos «defectos» femeninos: « ¿a quién podía dar la preferencia en mis discursos sino a la aniable, la piadosa, y la más bella mitad del género humano? [...] sepan todos, que el Pensador venera y estima a las Damas, como es justo, que les dirá francamente y con lisura su parecer, pero sin intentar ridiculizar un sexo, que es acreedor a todo su respetow (Pens. II, Pp. 1-2). Decía tener «ánimo de que nos tratemos con frecuencia» (II, 24) y, en efecto, a lo largo de la publicación, el Pensador se preocupó de las reacciones que pudiesen suscitar en las lectoras su insistencia en satirizar los comportamientos que consideraba frívolos:

"Quéjansi algunos de los que leen mis Pensamientos, de que la mayor parte de los que he publicado hasta aquí, se dirigen más a las Señoras, que a los Hombres; y no ha faltado quicn ha mirado esta preferencia cono un exicono poco cortés, y algo indecente. No me empeñaré en rechazar este baldón, bien que injusto. Baste decir, que si fuera menos apasionado de las prendas naturales, que adoman a las Damas, no repararía tanto en los defectos, con que suele afearlos en algmas la mala crianza, que les dieron sus padres, olos errados consejos de la lisonjas".

Guando los «espectadores» retrataban a sus supuestas lectoras o les hacian tomar la palabra, era para reforzar su propia autoridad moral a través de dos vías opuestas. Al representar a mujeres modélicas que elogiaban los efectos morales que las emseñanzas de estos reformadores tenían sobre sus propias vidas, inducían a las lectoras reales a identificarse con ellas y dejarse conducir por sus consejos, mientras que sus caricaturas de lectoras hostiles aspiraban a provocar rechazo, produciendo así el mismo efecto. Por ejemplo, cl modo en que una petimetra noble, rica y mundana narraba en su carta (pensamiento VIII) cómo se había convertido a las virtudes domésticas gracias a la lectura del Pensador creaba un efecto de realidad que hacía más persuasivo el mensaje y confirmaba la misión del "pensador", que había de ser el encargado de transmitir esa experiencia a las damas: «digales $\mathrm{Vm}$. al oído, que los respetos, y las veneraciones

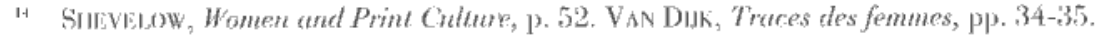

15. Pens, XVIl (1. II, 95-96). Similares observariones en t. I, pens. IV. 
no son Estados, que se heredan con d nacimiento, ni están afestos al trage, sino bienes, que se adquieren con la dulzura, la discreción, el juicio, y la modestia» (VIII, 20-21). Por e] contrario, la carta segunda del pensamicnto XJ V ponía en escena a un personaje femenino caracterizado para resultar antipático: l de una señora reacia a dejarse persuadir por un abnegado lector ("cl Martyr del Pensador») que pretendía convencerla de las bondades de la lactancia materna defendidas por Clavijo y Fajardo "ז. La "lectora correcta» del pensamiento VIll se permitía incliso, al reaparecer en wn número posterior (LXXX), reprochar al Pensador que fuese más severo en criticar los delesenos de las mujeres que constructivo, strgiriendo modos de col'egirlos, o eeuáninne, afeando tanbién los vicios dej otro sexo. Por elio lo acusaba de adaptarse servilmente a Jos intereses y gustos de una audiencia masculina, abandonando la imparcialidad de que debía laver gala un «espectador". De ese rrodo, al criticar pur boca de una lectora el sesgo de una prablicación que gustaba, en efecto, de proponcer una nueva moral familiar y sorial y un nuevo modelo de feminidad censurando los comportamientos de las mujeres (el cortejo, la vidi mundana, la crianza de los hijos a cargo de ayas y nodrizas), para defenderse seguidamente de esá aeusa-

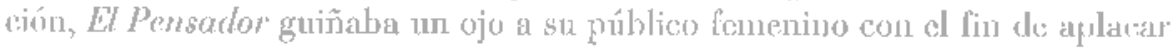
reacciones adversas, sin perder nunca de vista que no debía enemistarse our sus lectores, en su nayoría hombres. En conjunto, este periódico jugó con los recursos que le otorgaban las múlipiples voces que inturvoníar en la prensa de cosvumbros, alteruando declaraciones galantes y severidad reformadora, reconvenciones y guiños ocasionales a sus lectoras. Es1a polifonía, que daba mayor dinamismo y atractivo al contenido del periódico, dejaba, en última instancia. el camino abierto a las distintas interpretaciones que el público nusculino y fo:menino podía hacer acerca del modo en gite Clavijo y Fajardo presentaba las relaciones de los sexos.

El anzuelo polémico lanzado por el Pensador sirvió de pretexto a oura publicación para lanaarse al ruedo. El Hablador jucioso del abate Langlet, traducido por Nifo, se alzó como un auténtico «defersor de las damas» a la vieja usarza para prolegeolas do los agravios que, a su juicio, les había inflingido Cla-

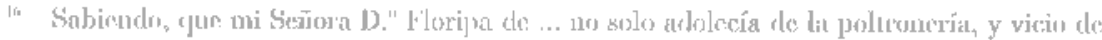

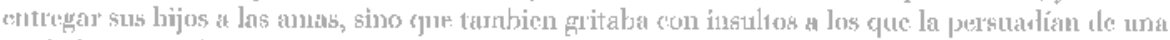

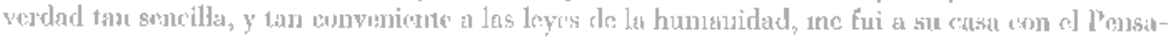

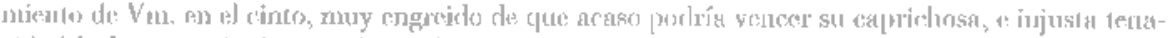

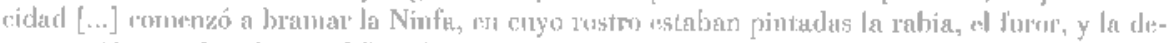

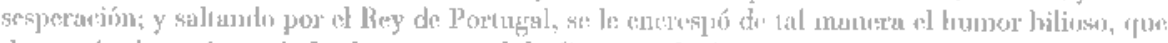

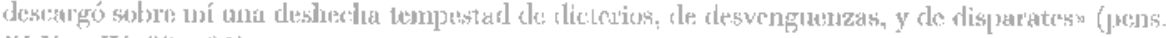
XLV, 1. IV, 80 y 81). 
vijo y Fajardo. En esa empresa, alternó entre adoptar la pose aparentemente objetiva de un "crítico imparcial» que ofrecía sus «dessapasionadas reflexiones» y exhibiv el lenguaje galante del que salía en «socorro» y «homenage» de las mujeres. Los argumentos de los que hacía uso, para atacar la idea de la inferioridad de las mujeres, en la "Carta a las Señoras. Nueva defensa de su sexo» que

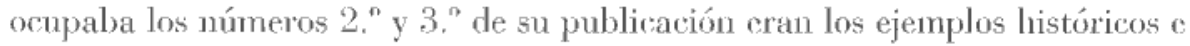
interpretaciones bíblicas clásicas en las apologías de las mujeres desde el siglo XV. Nuevo, no obstante, era el lazo de complicidad que establecía con las lectoras, exhortándolas a recupcrar su amor propio y no prestar oídos a quienes las persuadían de su "flaqueza". Con respecto a un texto como la «Defensa de las mujeres" de Feijoo (discurso XVI de su Teatro crítico), que tomaba a las mujeres como objeto de reflexión filosófica pero no las hacía sus interlocutoras. rste cambio en las estrategias de los escritores, que ahora cuidaban de dirigirse en segunda persona a las mujeres, se adaptaba a la evolución de las prácticas de lectura, insuflando así nuevos aires en un discurso viejo. También se erigió en defensor de las danas contra los «ultrajes» de ( 'lavijo el efímero Dichoso Pensudor de Valladares y Sotomayor (1766), que decía ofrecer a su público un «desagravio de las mngeres, sus prendas, excelencias y sublimidades» ${ }^{17}$. Pretendiendo adular a las damas sin enajenarse al público masculino, su prólogo ( $\mathrm{A}$ quien leyeres) se dirigía en primer lugar a aquélla para captarlas como lectoras: "Escucha, Muger, que para ti escrivo. Ya he alcanzado gran parte de mi deseo si me tienes en tus manos; falta prosigas el favor mirandome con ojos tuyos. quiero decir, con buenos ojos. Lee enteramente este, y los demas Pensamientos, y los hallarás labrados de glorias tuyas, y fortunas mias»' ${ }^{\prime \prime}$. A continuación, pedía a los lectores que recibieran con agrado la descripción de las perfecciones femeninas: "en estos Pensamientos, solo pretendo servir a las mugeres, diciendo lo que son, y agradar a los Hombres, desmintiendo con la verdad lo que muchos quieren que sean" ${ }^{10}$. En conjunto, su tomo, arcaico y cuajado de elogios sin

1" De esta publicarión, de la que Guinad no pudo comsultar nimgúm ejemplar, se conserva en lи B. N. el printer mínero.

18. Continía glosando ael honor de servirie, y la dicha de complacerte, que por esso me doy

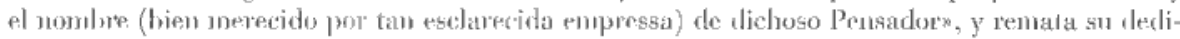
catoria con estas palabras: ofrezco, pues, a vuestrus manos, para qur eu sus paluas triunfe, una,

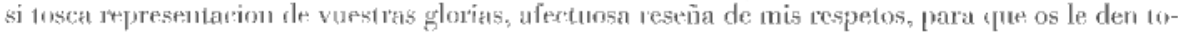
dos los Hombres si no como mereceis, gue no tiene termino, como mas elevadamente conceptuen.

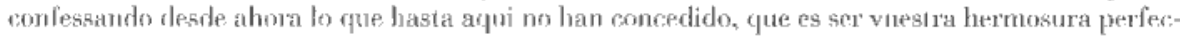
cion, y que en rodas las demás prendas que teneis, y expresarán mis Pensamientos, igualais, sino excedtris, a las suyas» ( $\alpha \Lambda$ quien leyere», prólogo al pens. I, sin paginar).

in aOye ya, lombre, que esta es tu vez, y empiezo cour rogarte á que me leas sin passion, y juzcues despues cono ella te dicte, que assi no te dexaras llevar en la sentencia del anor propio, ¿́ la parte que eres tís (ibidem). 
tasa, lo situaba más cerca de las convencionales apologías de la "excelencia femenina que del carácter burlón de los «espectadores» de los que toma su nombre. Quizá porque ese estilo ya no satisfacía al público del siglo XVIII, la iniciativa no sobrevivió a la segunda entrega.

En los decenios finales del siglo se produjeron algunas modificaciones en la representación del público femenino en la prensa. Por una parte, éstas respondían a la mayor variedad de formas periodísticas. Mientras que los «espectadores» de la llamada «segunda generación» en los años 80 manterúan la fómmula de articular su discurso en torno a un personaje central, los géneros miscéáneos que fueron imponiéndose en esos años no utilizaban esa ficción, de modo que en ellos la relación de autoridad, de guía normativa entre la voz del autor y sus lectores quedaba diluida en una estructura más variada y dispersa, que incluía relatos, anécdotas, reflexiones morales, artículos de divulgación cientifica o literaria y a veces informaciones locales. En segundo término, las listas de suscripción a la prensa de estos años permiten cuantificar la presencia femenina y así contrastarla con la representación literaria de las lectoras. Dieciséis suscriptoras tenía el tomo 1 del Espiritu de los mejores diarios literamos que se publican en Enropa en 1787, trece el 2," volumen del Correo de los Ciegos en el misno año, treinta y cuatro el Dirito de Valencia en su año de aparición (1790) y dierisiete en 1792. Asimismo, orhenta y siete damas madrileñas recibían entre 1787 y 1800 uno o más de los periódicos el Espítu de los mejores diarios, a Semanario enadito, el Memorial literario y el Comeo o el Diario de Madrid: aristócratas como la condesa de Montijo y la de Murillo, la condesa-duquesa viuda de Benavente, la duquesa de Osuna y la de Berwick, cuyos nombres figuran al menos en tres listas diferentes, pero también muchas mujeres no tituladas. Son estas cifras modestas, pero significativas, tras de las cuales se ocultarian sin duda ouras mujercs, lcctoras de publicaciones a las que estaban suscritos otros miembros de su familia o bien compradoras ocasionales de prensa ${ }^{210}$. Por último, en estos periódicos la participación del público sc hizo más frecuente y variada, multiplicándose las intervenciones femeninas en forma de cartas, artículos, poesias o soluciones de enigmas, y su tono, mpnos estereotipado, hace suponer que al menos algunas de ellas eran reales y no meros artificios literarios ${ }^{21}$.

20 Todas las cifras están tomadas de las listas de sugreripción de estos perjódicos en loss atios

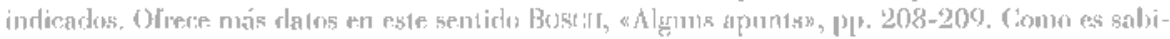
du, las cifras de suseripción representen lan sólo a una parte de lna lectores de una publicación, irmposible de delerminas, y que. Enctiso estima en torno a un 4 \% para la prensa perińdica (ENotiso)

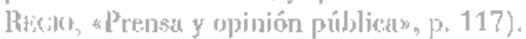

I Asi, por ejentuplu, Guinard opina que muchas de las cartas al Dirrio de Madrid tienen visos de verosimilitud (Gunara, La presse espughole, p. 228). 
El Censor, el más brillante y audaz de los «espectadores» de esos años, sustituyó la llamada al favor del público femenino por alusiones que daban por hecha esa aceptación, tanto en primera persona ( «hay algunas Damas que me son apasionadas»-t. I, n." XIII, p. 199) como, para darle más credibilidad, en boca de presuntas lectoras $($ Vm. que se ha grangeado tanta aceptación entre las Damas»-t. VIII, n." CXLIX, pp. 344-345-; "como Vmd. se ha manifestado siempre apasionado de las Damas" -t. VIII, n." CL, p. 365). Para hacer realidad esa imagen favorable, tomaban la precaución de preceder sus críticas de comportanientos femeninos (peinados, en t. II, n." XXVI; el galanteo, la ociosidad, la lactancia «mercenaria», en el n." CXXI) de mensajes a sus lectoras rogándoles que no las tomasen a mal, sino que apreciasen su intención reformadora $^{22}$. El negro retrato de un matrimonio infernal ofrecido por la carta de un supuesto lector iba acompañado también de la protesta de querer «estar a bien con el sexo» (t. III, n." LVII, p. 170). Y una de sus observaciones menos halagüeñas sobre las lectoras, la propuesta irónica de crear un periódico de modas que satisficiese los gustos frívolos de las damas (t. III, n. ${ }^{\circ} \mathrm{LVI}$ ), se escudaba tras la máscara de un remitente. Todo con tal de endulzar las críticas manteniendo la imagen de deferencia hacia el público femenino.

Aunque la participación de supuestas lectoras era escasa en las páginas de El Censor (sólo 4 de las más de 60 misivas remitidas aparecían firmadas por ellas), otros periódicos de su época las hacían aparecer con frecuencia para suscitar bien el rechazo o la identificación de su público y promover así, en cualquier caso, su adhesión a las normas propuestas. El Corresponsal del Censor de Rubín de Celis (1786-1788) incluía, por una parte, misivas que iban en el mismo sentido de las críticas del autor y las reforzaban con la ficción autobiográfica, como las denuncias de las vocaciones forzadas en los números 13 y 39 o la queja de una mujer sobre el matrimonio de interés en el n." 9. Ofrecía también cartas de personajes satíricos que ilustraban a contrario las posturas «racionales» y «normativas»: por ejemplo, la de una petimetra buscando esposo y la del petimetre que le respondía (núms, 6 y 12), o la de un marido que se quejaba de su mujer, siendo ésta una perfecta encarnación de los ideales ilustrados de comportamiento femenino ( $\left({ }^{\circ}{ }^{\circ}\right.$ ). Con estos recursos, trataba de inculcar en sus lectores y lectoras el valor de sus propios consejos para operar una transformación en sus vidas, autoridad moral que también asumía El Filósofo a la Moda (1788),

22 amar es querer á otro toda suerte de hien, y yo las ano muy de veras, para no estremecerme al considerar los males á que podria exponerlas ni omision. Asi que no llevarán á mal que procure hacer algw esfuerzo para remediar, si por desgracia estoy engañado en el buen juicio que de ellas tengo formado, unos ahusos que dan motivo á tantos clamores (disc. CXXI, pp. 1002-1003). 
adaptación libre e indirecta del Spectator a partir de una versión italiana, que pretendía impartir «a sus discípulos y discípulas», "lecciones instructivas para toda clase de personas», poniendo especial empeño en lá crítica de costumbres femeninas ${ }^{2:}$.

El vacio de una uprensa femeninan. Juegos de identidady autoridad en La Pensadora Gaditana

El interés de los editores por ganarse al público femenino y la obsesión, que ellos compartían, por construir y regular a la mujer que se decía ideal para una sociedad ilustrada, condujeron ad la aparición exs Europa de mia prensa específicamente destinada a las lectoras y que asumía una voz de mujer. En muchos casos estas publicaciones respondían á pluntas nuasculinas ocultas tras pseudónimos fenchinos, pero con cllus se abricron camino también las prineras mujeres perindistass". Englobando bajo la consideración de "prensa femenina" tanto los periódicos editados por numeres como bos dirigidos at ellas, faroline Rimbauli calrula que fuerom más de 100 las publicaciones de este signo rue. aparecieron en el siglo XVIII en distiutoss paises emupeos, sobre voclo en ligglaterra y lancian. Ll temprano desárrolío y especializición de la prensa en Ingrlacera, su amplia difusión y los c]cvados índices de alfabetización y lectura tuvieron como efecto la prorta aparición del primer periódico dirigido a las mujeres, The Ladies Mercury (1693), seguido por otros ejemplos a lo largo del siglo, vanto de tipo kespestador» como misceláneo, entre los que brillaron The Female Spectator (1744-1746), The Lady's Magnzine $(1759-1763)$ y The Iarty's Museum. Todos ellos contaban com una persona narrativa femenima, en ciertos casos un simple preudónimo y en otros correspondiente a una mujer real, como en la primera y en lis última de rstas publicaciones, editadas respectivamente por Eliza Haywood y Charlotte Lemiox. En Francia el desarrollo de esLe lipo de prensa fue más lardío. F ue en 1710 cuando inició su actividad la pri-

2. Ginnano, La presse espaghate, pp. 335 y ss

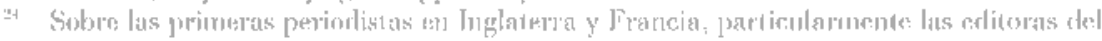

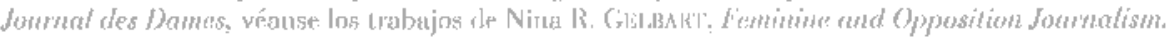

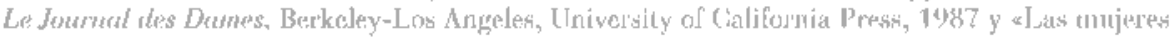

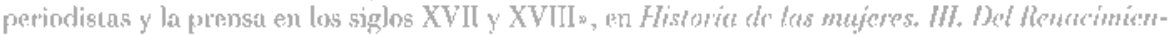

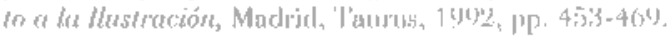

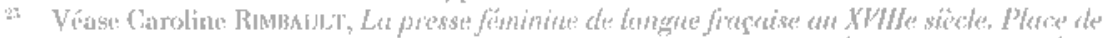

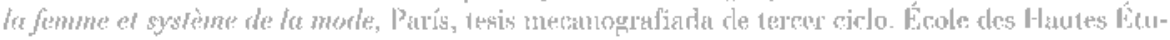

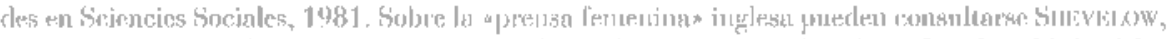

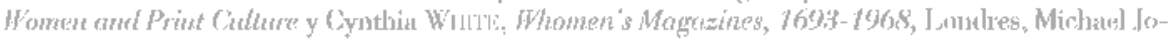

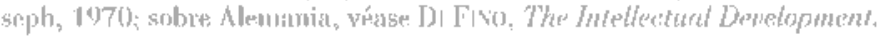


mera periodista, Mme. Dumoyer, al frente de un periódico de contenido general. la Quintessence des Nonvelles, y en fechas posteriores emergieron publicaciones destinadas a un público femenino, entre las que desiacaron La spectatrice (1728-1729, cuya autoría se desconoce) y la más longeva, Le Journal des Dames, dirigida alternativamente por hombres y mujeres. En Italia, la ilustrada Elisabetta ('aminer colaboró con su padre en L'Earopa letteraria, pasando a dirigirlo tras su muerte, micntras que en los territorios alemanes numerosas mujeres colaboraron como escritoras en publicaciones periódicas o, como en el caso de Sophie Mereau y Sophie von La Roche, dirigieron revistas para mujeres ${ }^{24}$.

La aparición de una prensa femenina era un fenómeno de consecuencias múltiples. Proporcionó a las escritoras un muevo terreno de actividad literaria y de beneficio económico, y a las lectoras, publicaciones que decian adaptarse a sus gustos y necesidades. Al hacerlo, no obstante, contribuían a encauzarlas por mos caminos determinados, suginiéndoles que eran ésas y no ouras las lecumas apropiadas para ellas. En Francia al menos, para los periodistas masculinos que cultivaban este tipo de prensa, éste constituía un paso por un género considerado menor y poco comprometido, en pos del ascenso en consideración profesional y literaria, y ocultarse, como hacían con frecuencia bajo un pseudónimo de mujer. les servia para tratar de ejercer ma influencia más directa sobre las lectoras o bien para buscar la indulgencia del público, lal como acusaba Ll Amigo del Bien Público a La Pensadora Gaditana: *oy logra la dicha de que una señora muger con el título de Pensadora, acreciente su número, dexandome con la duda, de si es D. "Bearriz de Cienfuegos la que piensa, o algun Pedro Fernandez, que en su nombre escrive, porque muchos Ingenios pusilanines, suclen valerse del salvo conducto de las faldas para evadirse de inpugnaciones» (dise. III) ${ }^{27}$. No obstante, a nuestro juicio esas voces femeninas en la prensa, aun cuando fuesen ficticias, podían actuar al mismo tiempo en otro sentido, quizá diferente del perseguido por los editores. Podían consolidar, sometiéndola a ciertas convenciones, la autoridad de las mujeres escritoras, propiciando así, aun sin pretenderlo, que la ficción se convirtiese en realidad ${ }^{2 k}$.

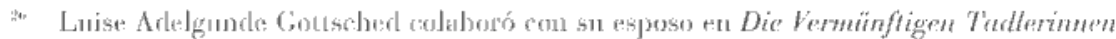

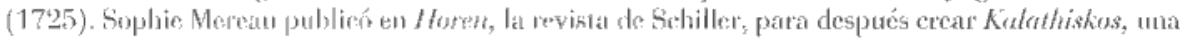

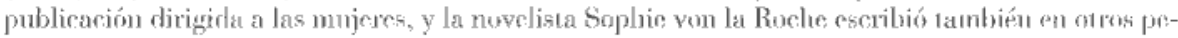

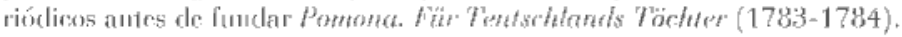

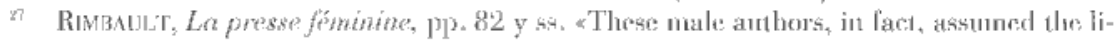
trary guise of women beraubs: they believeri readers an be particulaty indulgent of anyiling pro-

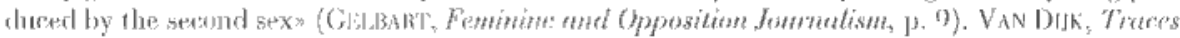
des jemmes, pp. 175-176.

2:1 Compurtinos a este respertu las resis de Shevelow y de S. M. Bonvoisin y M. Matguien. La presse feminine, Paris, PUl, $108,0,19.7$. 
En España la prensa «femenina» no se comsolidó hasta el siglo XIX, con publicaciones como el Correo de las Damas (suplemento del Diario mercantil de Cádiz) en 1807, y más tarde El Amigo de las Damas (1813) y El Periódico de las Damas (1822-1823) ${ }^{2}$. A finales del XVIII varias iniciativas se vieron frustradas al no obtener licencia de impresión ${ }^{3}$. De sus expedientes. que contienen los dictámenes de la censura y en ocasiones conservan algunos ejemplares, es posible, no obstante, extraer una idea del contenido y tono que sus autores consideraban propio de publicaciones para un público femenino. El Duende sevillano, proyecto que el impresor madrileño Manuel José Martín presentó al juez de imprentas en 1770 . era una hoja satírica que abordaba la crítica de costumbres con una acidez más próxima a la preisa "popular" del tipo de El Jazgado casero o El Duende de Madrid que a la prensa propiamente "ilustrada»: el dictamen desfavorable de la Real Academia de la Historía, considerándolo «un papel ridículo, que solo puede servir para una vana diversión y entretenimientos, determinó que no se le concediera la licencia ${ }^{31}$. Se divigía a las « damas» tuteándolas, en un tomo desenfadado y jocoso, alejado de las convenciones galantes de otros periódicos, que conlirma su orientación hacia un público menos culivado, y que sugiere que las mujeres constituían para esta publicación, a pesar de su título, menos un público potencial que un objeto de sátira al $11 \mathrm{so}^{* 2}$. Del Diario de las Damas que Juan Corradi envió para censura en 1804 la documentación conservada sólo proporciona una vaga idea de un proyecto que decía consagrarse a artículos

: Sohre la prensa femenina española pueden consuliarse las obras de Mercedes Roks, A warés de la prensa. Let mujer pn le Historia, Madrid, Instituto de la Mujer, 1985; Adolfo P'isinat a Isabel MAlizalis, Mujer, prensa y sociedad en Lspeña, 1500-1939, Madrid, 1980, e Inmaculada

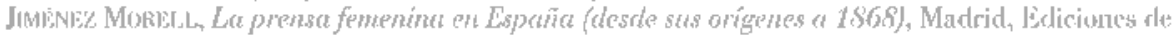

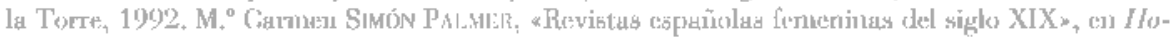
menaje a D. Agustin Millares Corló, Cran Cinaria, 1975, vol. I, jup. 401-445 es un complsto y detallado catálogo de cste género periodístico para el siglo XLX.

Cun Contamos a comlinuación taes de las tentativas que nencionamos. Del Diavio det Bello Sexo sólo se tiene la noticia, proporciona de por un erudi o del siglo XIX, J. Li. Liguizálial, y recograda

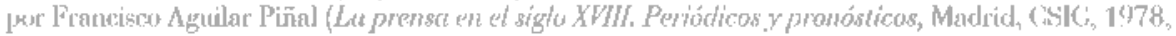

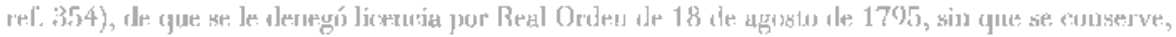
cono succde con los oros proyectos, documentación relative a la solicitud de impresión.

"H El cítulo completo es El Duende senillano. Chítica jocosa de los tajes, asos y modas re-

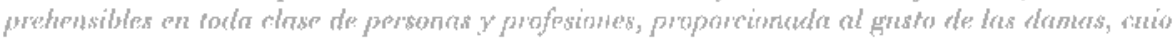
earacter y costumbers promete no ofender. Su cuthot al abate Palmini. La soliciual de impresion, denerada por iuforme desfavorable de la Real Acartenia do la Historia, se conserva en AHN, (onsejos, $55332-11(28)$.

42 El númeris manuscrito que acompañaba a la solicitud conticne una \&Deslicatoriát que hatse el Duende a las Damas de este P'ueblo plantadas en el Prado en comolies simones, propios o de manlas, 0 a pirs y con su perendengue ale cortejo al rulwo 
de «Ciencias y artes", "moral y otras materias útiles»" Escrito en estilo "sencillo y acomodado á la capacidad de coda clase de personas», el diario pretendia estimular la participación de sus lectoras convocando dos premios mensuales para quien resolviese cuestiones de historia, moral u otras materias planteadas en sus páginas.

Es, no obstante, d Lyeeo general del bello sexo o Décadas enuditas y morales de las damas presentado también en 1804 , meses antes que el Diario de las Damas, el proyecto que podemos conocer de modo más detallado, pues su expediente ineluye un proyecto y seis números manuscritos para examen de los censores ${ }^{34}$. Esta publicación decenal, ideada por Antonio Marqués y Lispejo. un echesiásico entre cuya producción literaria se contaban también varias connedias y dramas originales y adaptados, un Diccionario ferioniano, una utopia en forma de viaje imaginario, ma diatriba antifrancesa y otro proyecto periodístico fracasado, parecía proponerse tanto aleccionar como entretener y ofreces "amena instrucción» a sus lectoras, dedicaudo uma parte a «bellas letras» y otra a "variedades morales» "Contenía asimismo una sección de anuncios, que se distinguían de los que la prensa diaria solía dedicar a somparventas pérdielas y ofertas de trabajo porque se dedicaban únicamente a informaciones relacionadas con las mujeres de cierta condición: según rezaba el proyecen, daria snoricias de economía doméstica: de industria mugeril; de sus varias obras de humanidad para con los desvalidos, y necesitados; de los exercicios de devorion en las cofradias, hermandades, hospicios y colegios; y en fin de todos los actos de la conmiseracion y caridad de las Señoras", para Jo cual solicitaba a su público que le remitiese informaciones. Anuncaría también «la publicación de los libros solamente que puedan ser utiles a las damas, ó de que sean Autoras cllas mismas", así como "la colocacion de las mugeres en alguna havilidad particular pero $n$ o de criadas, Nodrizas y Amas de llaves \&es. Se trataba, por tanto, de una publicación que presuponía en sus lectoras, cn tanto que mujeres de una con-

"Lil expediente, conservalo en AHN, Consejos, 5567 (5), wo contiene el prospecto y varios números manuseritos que anmeia la solicitud. Las razones por las que se denego la licencia dampoco aparesen explicitadas en la documentación.

$\mathrm{AHN}$, Consejos, $55060(59)$.

15. Autonio Marqués y Lspojo, 1racido en 1702 en Guadalajara, estudió en la triversidad de Valencia y desarrolló nua anplia acrividad literaria. Las obras a las que nos referimos son el Virtge de un filosofo a Selenípolis, conte desconocida de los habitantes de la Tierra, Madtid, 1804; Higiene politica de la Españo o Medicina preservativa de les mates morates con que la comtagia la Framcia, Madrid, 1808; El plansible (licencia solicitada y denegada en 1806). Más daros sobre es1e autor y sus obras en Francisco At:HILiz PINAL, Bibliografia de escritores españoles del sigho XVIII,

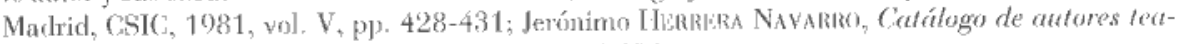
trates del siglo XVHI, Madrid, FUli, 1993. [p. $287-288$. 
dición social acomodada, intereses y gustos específicos, y, al asumirlo así, contribuía a crearlos a través del contenido y tono de sus páginas.

El prospecto y el artículo incluido en el n." 1 y titulado "El nuevo Periodista á las Damas Españolas» situaban las bases de la relación del autor con su públíro. En ellos Antonio Marqués hacía notar que la prensa femenina hábía sido hasta el momento inexistente y se jactaba de suplir una cartucia que impulaba al desprecio hacia la rapacidad intelectual de las mujeres. Se pretendía así toraldo de una nueva época y prescnraba su puhlicación como la respuesta q una imperiosa necesidad: la de proporcionar a las mujeres lecturas convenienIts. Cireada la necesidad, the atribuía el propúsito de savisfacerla y seprestaba providencialmentc a ser su maestio. Su «Liccom delinealua lus linuites a los que. debían circunscribirse las danas para ser. como tendían a exigirles los ilustrados, capaces de desernvolverse en lá conversación sim rivalizar con los hombres en el saber. A su juirio, éstas debían ceñirse a las leves tinturas de unos sabers "ámahles», como los relatos mitológicos que les of ecía en varios de sus números, y evitar los estudios usás áridos, pues no era su misión ser eruditas, sino construir la armonía del hogar voléndose an ef descmporno de las obligariones domésticas y aceptando con resiguacióm la infidelirdaul de sus maridos, a la vez que contribuir a mantener la armonía social cun sus actividades filintrópieas. lín cferto, el periódico otorgó gran importancia a las labores henéficas de lats

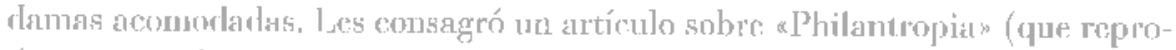

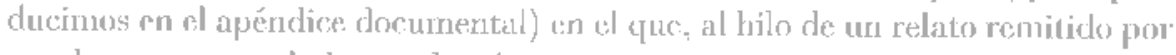
una lectora, in melodrama doméstico y sorial de feliz desendace, el periodista reflexionaba sobre el modo en que la paridart do las señoras acomodardas actuaba cimentando cl orden y reconciliando a los pobres con su suerte. I a misión que se les encomendaba encajaba a la perfreción com los discursos ilustra-

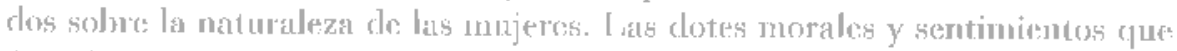
éstos les atribuian, la dulzura, el altruismo, la piedad, aparecian así como cualidades que las mujeres porlíar emplear no sólo pera asegurar la folicidad de sus familias, sino también para suavizar tensiones en la maquinaria social. Ésa serúa su contribución especifica a preservar pl orden y evitar las alteraciones populares que tanto hicieran temer los motines de 1766 y que la proximidad de la Francia revolucionaria y la crisis de subsistencias do fisales de siglo hacían especiahnente amenazanues. Por ello Antrmio Marqués y Espejo se propuso dar publicilad a esus acciones en su sección de anuncios, y justificó ante sus lestoras la aparente incongruenciá de que saltasen a la tribuna de la prensa actos que la modestia y la delicadeza obligahan a mantener en secreto.

El tono florido y un tanto condescendiente con que a lo largo de tordo el $L y$ ceo gentral del bello sexo el antor se dirigía a su público ("mi tierno auditorio», 
«el sexo encantador») retomaba, amplificándolas, las corteses apelaciones de la prensa anterior e introducía las fómulas galantes que se convertirian en obligadas en el siglo XIX. Por su contenido, sus intenciones y su estilo, este proyecto constituye un buen cjemplo de las implicaciones ambiguas que revestia el hecho de que los editores singularizasen al público femenino y le dirigiesen iniciativas específicas. Al hacerlo, limitaban el carácter de las materias que consideraban "propias» de las mujeres y así contribuían a difundir los nuevos modelos normativos de feminidad por tres vías complementarias. De una parte, el Lyceo se presentaba como la lectura más aconsejable para una dama, un compendio, sencilo y ameno, de todo aquello que le era lícito y convoniente saber y una alternativa a otras lecturas que dobía evitar. Al mismo tiompo, se arrogaba la autoridad para ser no sólo el mentor de sus lecturas, siuo también, a través de sus lecciones de moral, el gúá de su conducta social y privada. Por último, ofrecía a las señoras una tribuna donde los actos y méritos que definían a ma perfecta dama cristiana e ilustrada, muy espocialmente la benelicencia, se diesen a conocer y cosechasen los aplausos públicos. El tono patcrnalista que para estos propósitos adoptaba el autor, su invitación a pue las lectoras participasen, la imagen aduladora que de tlís daba y el caráter luertenente moralizante de los contenidos pervivieron en posteriores publicaciones, deste el liberal Periódico de Lrs Damets (1822-1823) al conscrvador Comeo de las Damas (1833-1835) o el efímero (Otservatorio Pintoresce (1837). Aunque la iniciativa de Antonio Marqués y kspejo no llegara a materializarse, al cxpresar su dietamen favorable el censor Pedro de listala consideró que los perfiles de esta publicación concordaban con lo que los guardianes de la sconveniencia» y «utilidad» de los impresos que veían la laz contemplaban como arlecuado para las mujeres:

"me parece que uu periodico de esta nauraleza podrá ser ulil, si con el se logra que las mugeres se apliquen á teer y aprendan las cosas que les son necesarias para al mejor desempeño de sus obligaciones que diemen o pueden bener cul la sociedacts

Antes de que estas tentativas lracasadas se sonetiesen al juicio do los censores, vieron la luz dos periódicos firmados por sendas mujeres: la Pensatriz Salmantinn de "Escolástica Hurtado», publicación anunciada en la Gracete de Madriel de 20 de mayo de 1777, de la que no se conserva ningún ejenplar, y la Pensadora Gaditana de "Beatriz Cienfuegos». I Los títulos de ambas se inspiraban en la ola de «espectadoras» aparecidas en Europa tras los pasos de La Spectatrice y The Femele spectator, pero, como sucediera con alguna de cistas, es

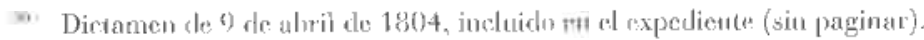


muy posible que fuesen obra de dos hombres, dos eclesiásticos". No obstante, aun cuando probablemente no se tratase de mujeres de carne y hueso, la aparición de publicaciones periódicas con firmas femeninas suponía en sí misna una novedad en los años 60. Que los escritores adoptarau pseudónimos femeninos era en el siglo XVIII una estrategia habitual, mientras que en el XIX, cuando la ideología de la domesticidad cristalizó de forma más cerrada e imperativa, serían las escritoras las que se verían con frecuencia forzadas a publicar sus obras bajo una falsa identidad masculina. El recurso a un disfras de mujer tenía inrenoiones diversas segúm los casus. (ion él los periodistas trataban de captar al público femenino y de revestir mayor autoridad a sus ojos para sugerirle cambios de conducta. Les daba también la posibilidad de adoptar poses reióricas (por ejemplo, de defensa de la superioridad femenina) en busca de un efecto de notoriedad o, al contrario, de lazzar críticas audaces a la desigualdad social entre los sexos para neutralizarlas a través de la ironía y la paradoja. Pero, más allá de las inenciones de los periodistas, el público podía hacerse sus propias opiniones acorca de estas «mujeres» que tan resueltumente comahan la pluma. Aunque no podamos aportar ulteriores datos para levantar la núscara de «Beatriz Cienfuggos», La Prnsadora Gaditana permitc apreciar cómo se consuruyó y se ofreció a los lectores y lecturas una identidad literaria femenina. La forma en que se presentaba como autora, el diálogo que mantenía cou su público y el papel que ejercian las lectoras en esa publicación dan pistas sobre el impacto que esta representación de la mujer escritora podía tener sobre el público de ambos sexos.

De acuerdo con las imposiciones del género periodístico en el que se inscribía, la Pensadora asumía desde el principio una posición de autoridad con respecto a sus lectores y lectoras, a quienes se dirigía, como era lo propio de los "espectadores", para inspirarles reformas morales en sus vida. I Itilizada en lemenino, esta forma de presentarse constituía uná novedad, por cuanto dilería de la convención generelizada que exigía de las unujeres escritoras mostrarse humildes al ofrecer sus escritos al público. Sólo en raras ocasiones se amoldaba la Pensedore a este patrón de modestia, reconociendo «la debilidad de mis fuer-

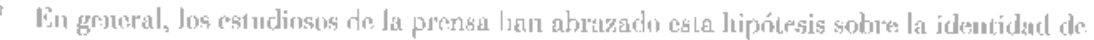
la Perasadora, a partir de una obsesvarión de Ciambiasso y algunas sosjechas que esk la propia épo-

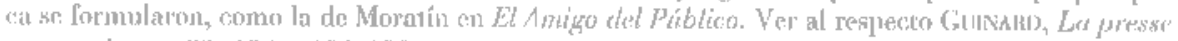

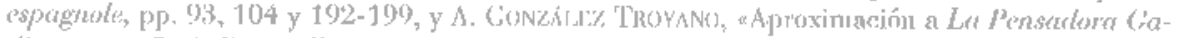

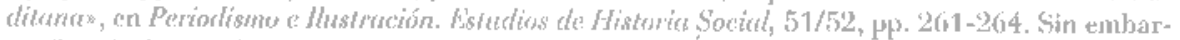

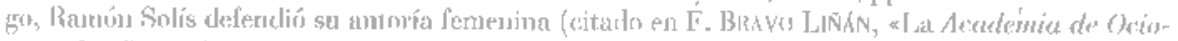

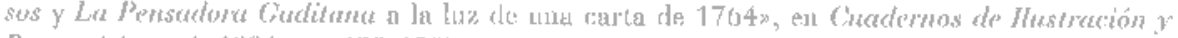
Romanticismo, 1, 1901, pp. 129-130). 
zas" (pens. I, 9) o atribuyendo su éxito a la benevolencia debida a su sexo (pens. XXVII). En otros pasajes criticaba precisamente los artificios de la falsa modestia y se presentaba como ma inujer dotada de "prendas que me distinguen y me exceptúan del comm de las mugeress $(I, 15)$. Se mostraba llena de autoridad moral para censurar los comportamientos tanto femeninos como masculinos y empleaha para ello un leuguaje enérgico ("corrige», "amonesta»), osando equipararse incluso con Catón o Licugo (I, 1 y 5). Como otras "espectadoras" europeas, se retrataba a sí misma haciendo de su edad respetable y la independencia de su estado elementos que le permitían ejercer de árbito de cuestiones morales, y en particular, en las disputas conyugales: "Mi edad es entre merced y señoría, lo que basta para dar consejos acertados, sin que sea preciso escucharlos con disgusto: mi inclinación es la libertad de ma vida sin la sugecion penosa del matrimonio, ni la esclavitud vitalicia de un encierron ${ }^{3 *}$. Inédito también dentro de los cánones que regían la presentación de las escritoras era el hecho de que apareciese como una profesional de las letras que perseguía asegurar cou sus ganancias su independencia material, haciendo alarde de renunciar al matrimonio para conservar su autonomía y su oficio. Cuando un lector le proponía casarse con él, prometiendo respetar su dedicación literaria ("y no tema que la he de quitar el escrivir, pues antes de cstas maneras ayudará con sus discursos a los gastos precisos de la casa»-pens. XV1, pp. 60-61), le respondía con una reflexión sobre el matrimonio y acababa rechazando al pretendiente:

"déxeme Vm, pensar a mis solas, que regularmente el estudio ni pide compañía ni otros cuidados, pues me hasta el que tengo de sufrir a $V_{m}$ y y otros muchos las impertinentes críticas que lomentan sobre ni obrilla, a la que ya que no pueden morder por su objeto, se desvelan en indagar otras cireunstancias que wo vienen al caso ni son del asunto, como la que Vm. apunta de los motivos que han obligado a mi pluna a pensar" (XVI, pp. 73-74).

No era en su talento o en su formación en lo que se basaba la Pensadora para legitimarse como escritora, sino en los beneficios sociales que lograría su tarea reformadora. De ese modo podía responder a las objeciones que algunos lectores formulaban, advirtiéndole que «corregir abusos y desterrar preocupaciones es propia obligación de entendimientos águilas que saben mirar al Sol de la razón cara a cara sin cegarse, pero a una pobre Señora, que toda su erudición no pasará la línca de así, así, y que su librería se compondrá de quatro no-

: Pens. I, 11. La publeación inglesa The Old Maid (175.5) estaba finnada por una tal * Mary Singleton, spinster», es decir, «solteronda (WIITr, Women's Magazines, p. 30), mientras que la radical Spectatrice de Camusat (1728-1729) hacía gala de su resuncia al matrinonio (CHLBART, Fetminine and Opposition Jounalism, p. 22-23). 
venas, y 5 o 6 devocionarios, ¿qué podemos esperar, ni qué noticias interesantes nos podemos prometer?" (pens. XIX, 127-128). Al pretender que no tenía aspiraciones literarias, sino morales, y reprochar a los lombres que buscasen en las letras sólo la gloria ("más delinupuente, indigno y despreciablé es en los hombres el entregarse a saber solo por la vauidad de lucir en público, y no por la forzosa intención de aprovecharse de su ciencia paru gobernar su conducta -pens. XIX, 14-), alirmaba su autoridad como escritora sobre un argumento 'jue fue muy útil a las mujeres de letras. Defender su derecho a disertar sobre mortona y moralidad para anoregir abusos y desterrar preocupaciomess les dio mayores posibilidades de tomer la pluma y publicar sus producciones, a la vez. que las obligaha a enarbolar siemipre propósitos morales y disimular sus ambiciones literarias:

*Que las verdades que trato (dicen con ayre decisivo) y los asuntos que: voco no sm competentes at una muger, porque no se mira adoruady de la autoridarl necesariu para comegir y diserlar verdades. Yo halúa igmoralo hasta álorá que todo rarional, en especial las rle ni sexu, no podían hacer discursos sobre las verdades más importantes a la suciedact, sin estar adomadas de tioulos,

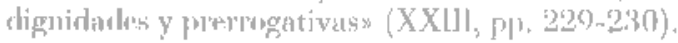

La Pensadora no parecía dirigirse a un público exclusivamente femenino, sino a una audiencia de ambos sexos a la cual procuraba contentar igualmente. Así, en su presentación Beatriz Cienfuegos se erigía, haciendo uso de un lenguaje luelinoso y de resonancias marciales, en represcntante de las mujeres para responder a la parcialidad del Pensador criticando los conportamientos masculinos ( «eñoras mías, ya tienen Vms. quien las vengue; ya sale á campaña urá mnger que las desempoñe»). No obstante, en el siguierite número se proponía iniciar la labor reformadora por su propio sexo y anticipaba la posible reacción airada de sus loctoras: «Todas sostarán en la inteligencia de que dará puineipio ni género epensarlor» por las extravaganeias de los hombres, dándoles una mano como se merecen, desquitando en parte las muchas que nos deben; pues no. Señoras mías, si Vins. lo aguardaban, tengan paciencia y aguanten, que la caridad bien ordenada principia excreitándose en cosa propia, y puiero primero que me debar un aviso y una reprehensión, porque como las ano de veras y soy interesada en sus ariertos o desharros, intento apagar el fuego de casa antes que al vecino» $($ II, 20) 20 .

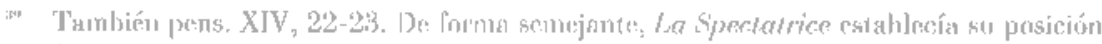

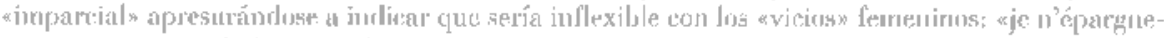

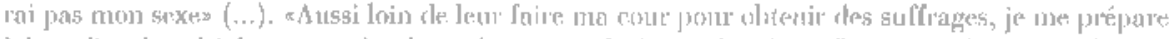

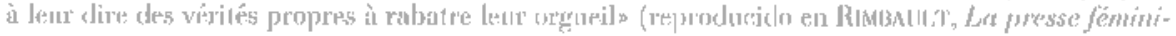
ite, $p, 323)$. 
Si la actiund de la Pensadora hacia las nujeres alteruaba la severidad, la solidaridad y la adulación, la relación que establecía con sus supuestas lecioras era también en cierto modo ambigua. Reales o fieticias, éstas inundaron las páginas del periódico de cartas y opiniones, en una proporción mucho mayor que en otras publicaciones coetáneas. Algunas de sus misivas se limitaban a relatar um problema y solicitar el consejo de Beatriz Cienfuegos. como la carta de la esposa de un hombre avaro (pens. XXXII) o la de la viruosa suegra de un yerno reprobable (pens. XXXIX). Otras, cono la de una madre mundana en el pensamiento XIII o la de ma petimetra que pretendía dominar a su marido en el XXX, encarmahan los "vicios» denostados por la Pensadora, realzando así, por contaste, los ideales de feminidad que ella defendía: el ejemplo de una petimetra domesticada por su marido, fervoroso lector de La Pensadora (pens. XXXIII), venía a representar en la ficción el efecto moral que aspiraba a provocar con sus reflexiones. Lectoras modélicas o estereotipos satíricos, estas liguras, que eran presencia frecuente en owras muchas publicaciones, ejecian en este periódico el mismo papel persuasivo o disuasorio. Más sorprendenues y monos usuales eran las lectoras «rebeldes» que llevaban sus eriticas de las costumbres sociales desfavorables a las mujeres mucho más allá de lo que iba Beatriz (ienfuegos, o que se permitían disentir con ella. En este caso, los personajes de lectoras parecían revestir la función de aller ego de la Pensadora para expresar lo que aquélla no se atrevía a decir, como sucedía en la carta de "La Desengañada" (pens. IX) o el pensamiento XXVII, que reprobaban la doble moral sexual, la tolerancia de las libertades amorosas de los hombres y la severa censura que recaía sobre cualquier veleidad de las mujeres. Las «lectoras" cuyas cartas se reproducían en los pensamientos IX y XXVIII llegaban más lejos, poniendo en cuestion a Bcatriz Cienfuegos. Le reprochaban que, traiciomando sus declaraciones iniciales, no fustigase con suficiente energía los vicios masculinos. y por ello se permitian tomar la palabra en su lugar para denunciar en tono exasperato las «iniquirlades» do Jos hombres:

"Muy Señora mía: ¿Es Vmo la que en principio de su obra salió haciendo alarde de ser muger y que como wal no dexaría a los hombres hueso sano, pues dirigiría su phuna contru sus disparates? ;Bellamente ha cumplido su palabra! [... ¿ ¿ lis posible que no haya habido ma dama que tomando la pluma la ofiecisse asunto para cue emplease útilmente su crítica contra los hombres, liaciendo maniliestos sus rlifparates y descubriendo sus extravagancias? [...] Obligarla de nstos motivos, y deseosa de que se vea en la serie de sus papeles má carta femenina que forma justamente una crítica contra tanto cono nos hacen padeer los señores de la cámara alia, sale mi pluma al numdo amuada te razón y defendida de vodas las leyes de la naturaleza, para que vean que también en muestros países se sabe hablar en crít ico y sobta aliento para publicar las iniquidacles que sufrimos baxe el desapiadado dominio de su esclaviturd, pues ésta se diferencia en muy poco de la libertad racional» (XXVIII, pp. 26-29). 
Además de crear la apariencia de discusión y el ambiente de polénica que era característica en los kespectadores» para resultar más amenos y atractivos para el público, estos roces entre la Pensadora y su audiencia de ficción se prestaban quizá a un doble juego para contentar a los dos sectores del público. $A$ las mujeres irían dírigidos los discursos más severos para con los comportamientos masculinos, la belicosa derlaración de intenciones de "Bea1riz Cienfuegos»e incluso las cartas de las alectoras" que respondían al liamamiento de ésta y llegaban a sobrepasarla en audacia ${ }^{42}$. En cambio, la persistente crítica de las costumbres femeninas reflejaba las olssesiones de su tienpo, a la vez que buscaba, quizá, suscitar la complicidad de los lectores. La Pensadora Gaditana parecía proponerse, pues, introducir en el panorama periodístico español un modelo nuevo, auncue ya experimentado en otros países, sin correr el riesgo de enajenarse a ningún sector del público. No obstante, lá fórmula de una «espectarora» en lemenino, ann cuando seя muy dudoso que liese ına mujer su verdadera autora, introdujo rasgos nuevos, diferentes de las convenciones al uso, lanto en la representación de la escritora como en la del público femenino. I a Pensadora se singularizaba como «autora por sn rechazo reiterado al matrimonio paral volcarse en su empresa noral y literaria, por su falta de una actilud consisirnte de modesila y por su condición de mujer de letras que vivía de su plumil. Lals «lectoras», mucho más presentes y activas que en otrás publicaciones coetáncas, destacaban por el atreviniento y la scguridad con que intervenían en el periódico para dar sus opiniones y discrepar de las actitudes de la autora. Cuál fucra la imagen que de estos personajes fielicios llegara a los lectores y lecetoras reales, es dificil saberlo, pero la rovedad de estats representariones activas, belicosas y ambiguas debió dejar hucllas, tanto positivas como negalivas, on la opinión social sobre las mujeres de letras.

Lá identidad femenjua que asumjó La Pensadora un sólo condicionó las formas en que ésta se presentaba ante su público y entablaba relación con los "lectores» y klectoras» que le escribían, sino que también influyó sobre la reacción de la crítica. Beneficiada de un notable éxito en su momento, que impulsú

+1) En el n." 29 la Penserdoriz reconocía o fingia, ufañu, la amplia acogida que su pulblicación

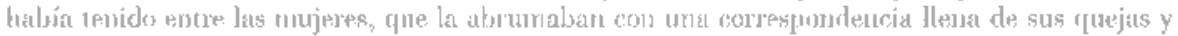

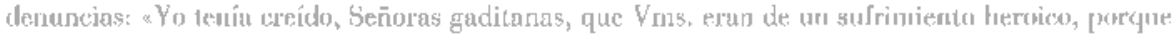
esperando con no pora impaciencia algma cturte femenima que criticase los delectillos de los homtres, solo lie: visio que con un porfiado silenecio han sufrido los golpes de ntis Pansamicntos sin luablar una palabra, pero despues que har notado abied to el carriro, y que la salider al público una dama tirando taxos y reveses sin temer a las zesulths, fne veo tan licna de cartas que discurre se han

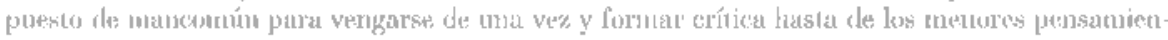
los de los ainorentes lionibress (XXIX, pp, 54-55). 
la recdición del periódico en 1786, La Pensadora recibió amplios elogios en la carta que remitió un supuesto lector a otra puhlicación gaditana, la Academia de Ociosos de Flores Valdespinot1. El remitente realizaba una comparación entre ambos periódicos que era desfavorable a la Academia y lisonjera para su predecesora y rival. Pero lo más interesante de su crítica es que utilizaba el sexo de su «autora» como argumento en la discusión. Por una parte, describía las características de una y otra publicación como si fuesen un natural reflejo de las cualidades innatas de hombres y mujeres, y así contraponía el carácter serio y erudito de la Academia a la variedad y vivacidad de expresión de la Pensadora. En segundo lugar, apelaba a la caballerosidad para afear a Flores Valdespino que hubicra osado criticar a la Pensadora, en lugar de respetar la «delicadeza» que le imponía su condición de mujer. Este testimonio muestra cómo las conveneiones operaban sobre los periodistas cuando éstos se enfrentaban a un texto escrito por una mujer, si es que creyeron en la identidad femenina de la autora, u ofrecido bajo ese disfraz, si acaso los editores de la Academia entraron deliberadamente en el juego de la ficción.

Disfraces femeninos en la prensa de finales de siglo

En los decenios finales del siglo proliferaron como nunca lo habían becho en la prensa las colaboraciones femeninas. Cartas y poesías de mujeres se publicaron con frecuencia en los «espectadores» de esos años y, sobre todo, se engarzaron en la estructura más libre de las publicaciones de tipo miscelámeo: diarios, como los de Madrid. Valencia o Barcelona, semanarios, como el Correo literario de Murcia o el Semanario erudito y curioso de Salamanca, o publicaciones de contenido literario, como el Diario de las musas. Algunas de las personas que sc ocultaban detrás de psendónimos o iniciales eran mujeres de carne y hueso, como lo eran, entre las decenas de firmas femeninas rubricando poesías publicadas en la prensa que recogiera hace años Aguilar Piñal, «Madama Abello» (María Martínez Abello), Antonia Araujo, Joaquina Arteaga, Isidra Rubio, Juana Verge, Clara Jara de Soto o Rosa Mazaorinit.2. Su aparición en las páginas de los periódicos no hacía, por tanto, sino reflejar la relativa floración de mujeres que en la segunda mitad del siglo accedieron a la escritura y la pu-

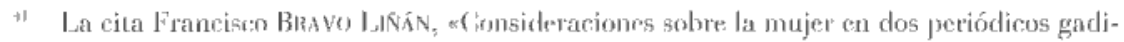

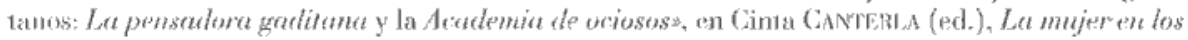

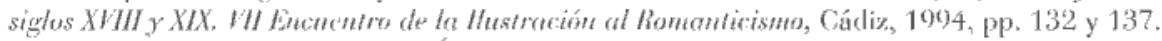

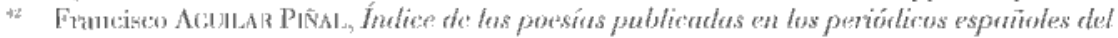
sigh XVIII, Madricl, (SSIC; 1981. 
blicación, dessle las más conocidas, como Josefa Amar, M. "Rosa (Gálvez o Mar'garita Hickey, a numerosas autoras de poesía o adaptaciones teatrales hoy olvidadas". De otras, que adoptaban los nombres de "Amarilis», "Justa la curiosa”, «La Madama de la X», "La observadore», "La principiante», "La sensible», puede sospecharse que eran ropajes que ocultaban a los propios periodistas. De hetho, istos parecian complacerse y entretener a sus lectores sembrando durlas y representando en sus publicaciones un juego de intriga en el que las identidades sexuales se veían cuestionadas. De «D." Leonor», colaboradora habitual del Disuro de Valencia desde 1791, se supu años más tarde que era el mismo diarista que también fimmaba "R.A.» 0 "El Ingenuon, nientras que una queja que «La madrileña andaluzada» publicó en el Diario de Madrid de 9 de abril de 1796 contra su esposo, porque éste no le permitía emplear lacayos con librea, recibió una respuesta de "La delensora de las madrileñas" que se explayaba contra «el bufón, que fingiéndose muger, escribió la carta insertu el día 9 de es-

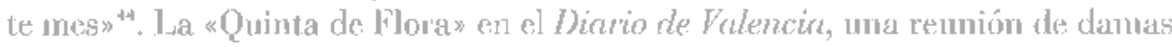
cultas que pretemdjan comstitnirse en mad academia erudia y literaria, acla-

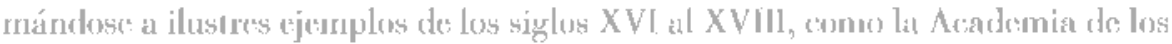
Nocturnos, la del conde de Alendia, la Academia Vaberciana de Mayants o la de

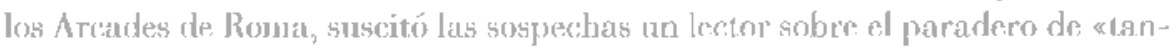
to régimen, tanta energia, tanta clegancia, tanta prosopopeyas, y finalmente be desvaneció como el homo enanto un artículo descabrió que no existía lal quin va ni sus ilustradas habitantes $\mathrm{g}^{\text {ti. }}$.

l laciendo aparecer con tal frecucncia a mujeres colaboradoras y al mismo riempo fomentando la duda sobre su verdadera ideritidad, los periodistas jugaban un juego ambiguo. Por una parte, contribuían a familiarizar a su público con la ligura do las escritoras, enfrentándolos cotidiamamente con textos que decían ser obra de nujeres. Algmias de ellas aparecím como mujeres prestas a saltar en telensa de su sexo frente a las opiniones vertidas por los periodistas o por otros lectores, como «La defensora de su sexo» en el Correo literurio de Murcia (n." 158 a 160, 8 a 11-IIJ-1794), "La defensora de las Madrileñas» en el Dia-

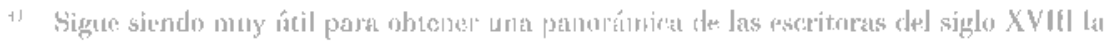

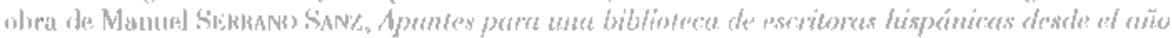

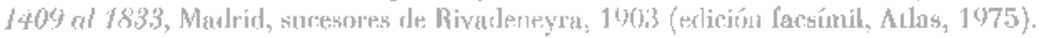

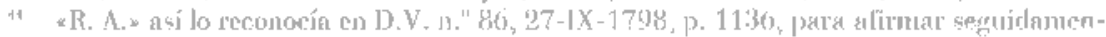

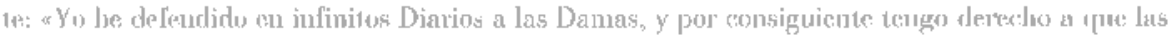

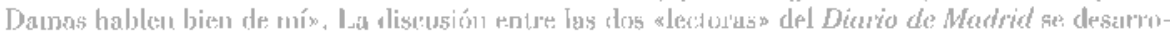
llá én los númes. $100(9-I V-1796)$ y 110-111 (19 y 20-IV-1796).

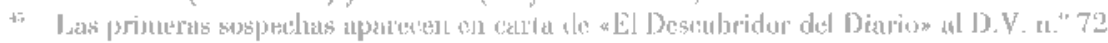
(10-1X-170) 1), y la desuulorización delinitiva em D, V, u." 97 (5-X-1701). 
rio de Madrid (19 y 20-IV-1796), "La muger imparcial», autora en el mismo de una «Carta al Diarista acerca de los derechos que debían en la sociedad tener las mugeres» (D.M. 8-XI-1803), o la anónima firmante de "Quien haga aplicaciones, con su pan se lo coma. Carta de una dama a D. Isidro Calle Boceca en defensa de las mugeres» (D.M. 10-VIII-1795). Sin embargo, de muchas se daba una imagen frívola, como de las petimetas que se apresuraban a defender los usos indumentarios que merecían los reproches de otros lectores ( "Carta en defensa de las colas de faldas» de La Petimetra», D.M. 12-VIII-1795; "Carta al Autor de las cartas sobre las colas»; «D.“ X», D.M. 20-VIII-1793), de la lectora que se proclamaba sin recato xprodigio de erudición en todos los ramos del saber» (D.M. n." 222, 10-VI]-1795), o de aquéllas a quienes otras afeaban su tono pedante (ídem, 1." 30 y 31-I-1796). «Vmd. no pudo resistir a la tentación de ser autura, y pecóx: acusaba ma mujer a otra que se había atrevido a criticar a un colaborador del periódico, «D. Isidora Calle Boceca», y en ese reproche estaba implícita la desconfianza que seguía pesando sobre el hecho de que esas mujeres imaginarias, instrumento de los diaristas pero a la vez imagen de sus inquietudes, hiciesen uso de la escritura.

En efecto, si a través de los pscudónimos femeninos los periodistas contribuían a normalizar la imagen de la mujer escritora, también dictaban las normas a las que debía ajustarse y punían en evidencia a las que se situaban fuera de esa línea. Buen ejemplo de cllo son las actitudes que adoptaban al plantear una discusión entre «D. Leonor Utanda de Castro», colaboradora del Diario de Madrid, y otros personajes masculinos que le respondían y entablaban polémica con ella. "D. "Leonor» se había interrogado, en cl número correspondiente al 1 de septiembre de 1797, sobre las causas del conflicto entre padres e hijos, no sin insinuar en el preámbulo sus dudas sohre el reparto sexual de funciones que reservaba a los hombres las Artes y las Ciencias y restringía a las mujeres a los cuidados domésticos. En el debate subsiguiente «EI soltero respondón» expresó su convencimiento de que los vicios de los hijos se debían en buena parte a la ignorancia de sus madres y propuso, como buen ilustrado, mejorar la educación de las mujeres, pero precisando que no se trataba de "hacerlas bachilleras, ni doctoras, ni eruditas\%, una advertencia que parecía lanzar directamente contra las pretensiones de su interlocutora (D. M. n. ${ }^{\circ} 27-X-1797$, pp. 1265-1266). Por el contrario, era una actitud condescendiente y no beligerante la que tomaba con D. "Leonor "El Glosador», quien en su respuesta se decía lleno de "compasion y ternura, á vista de las lagrimas, que derrama una infeliz inuger, deseosa de saber lo que ignora» (D.M. 29-X-1797). Ser tachada de «bachillera», como reprochaba «D. Isidro Calle Boceca» a una lectora que disentía de sus opiniones sobre la belleza en el diario de 28 de julio de 1795, o como implicaba el 
pseudónimo de *Mari Savidilla» adjudicado a otra lectora que ascribía a los diaristas «sobre la pureza de la lengua castellana» (D.M. 14 y 15-IX-1799), era la amenaza que planeaba sobre toda mujer que se atreviese a saltar el espacio entre la lectura y la escritura, ofreciendo sus opiniones en público en lugar de guardarlas modestamente para sí. Restringirse estrictamente a escribir sobre los teuas que se consideraban adecuados para las mujeres y hacerto con una actitud humilde que guardase la debida deferencia al juicio de los hombres era el ínico modo de evitar tal haddón. Ese conflicto, que fue el de todas las escritoras de la época, aparecía representado en la prensa, tal como ilustra, de forma muy significativa, el diálogo que sostuvienon en las páginas del Semruario de Salamanca en 179,5 un hombre y una mujer a propósito de cicrus obras litararias. La corresponsal lemenina, una supuesta lectora que fïmaba tan sólo con una enigmática "S», conseguía que su interloxutor aprobase sus reflexiones y las culificara de «juiciosas», a costa de acatar ciertas normas tácitas. En primer lugar, expresaba su opinión sobro sus lecturas como si se tratara de una corrcspondencia informal y privada y no de críticas literarias elaboradas fura su publicación. En segundo término, se negaba a dan su parecer sobre un género considerado poco "lemeninos, la poesía épica (aduciemdo para excusarse tanto su (lesconocimiento de la materia cono «los cuidados caseros» que la acuciaban) y la ofrecía, sin embargo, sobre una novela sentimental, Sare Th..., traducida por una mujer, Antonia Río y Arnedo, y otra novela didáctica de personaje lemenino, La Eudoxia de Montengón. De cse modo lograhá eludir el calificativo denigrante de "bachillera» que su interlorusor había hecho recaer sobre M." Ro" sario Masegosa, “La Señora uraductora de las Cintas de una Peruana», tantu como la opinión de éste de que «las mugeres lean, y no citen ni critiquen». A través del personaje de estu lectore «opinante*, se transmitía la idea de que las mujeres podian lacer lecturas críticas y atreverse el enjuiciar las obras de otros antores sólo si tomaban la precanción de no traspasar los límites de fo ruc s* presentaba como \&conveniente» para ellas ${ }^{4 /}$.

Así pues, cortejadas por los periodistis, las lectoras, o más bien la inagen que de cllas se mepresenuban éstos, contribuyeron a modelar la prensá del siglo XVIII. A su vez, com el pretexto de adaptarse dócilnente a las preferencias de su público, ósta se empeñó on dar forma a la lectora modélica y, más anulià-

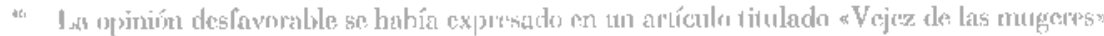

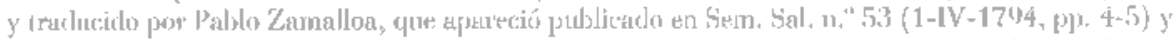

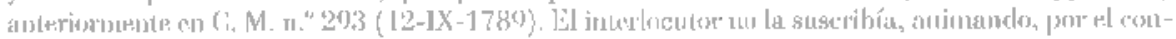

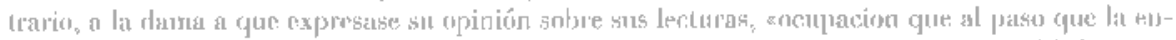

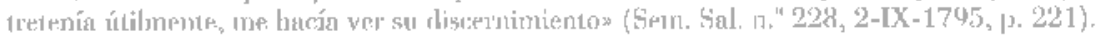


mente, a la mujer deseada por los ilustrados. Por su parte, los pseudónimos femeninos con los cuales los periodistas fingían que sus lectoras daban el salto de la lectura a la escritura contribuyeron a dibujar un marco en el que la actividad literaria de las mujeres aparecía como socialmente aceptable, pero se inscribía dentro de unas estrictas normas fuera de las cuales se representaba como ridícula o bien amenazante.

\section{APÉNDICE DOGUMENTAL}

Lyceo general del bello sexo o Décadas eruditas y morales de las Damas. Expediente de solicitud de licencia para la impresión (selección). AHN, Consejos, $5566(59)$, manuscrito sin foliación.

\section{Prospecto}

"Pasaronse ya las injustas ideas, conque denigrando el merito del vello sexo, ó se le hacia incapaz de la instruccion literaria, ó se le juzgaba muy perjudicial con tan brillante adomo. Desasidos oy generalmente de semejante preocupacion, se save buscar en las Damas el delicioso encanto de su espiritu, anteponiendole á los perecederos atractivos de sus gracias.

Es evidente que el cultivo del entendimiento hace mucho mas amables la juventud, y la velleza; como tambien que él presta un dulce consuelo cuando estas faltan: motivos por los que la sociedad exige que en estos tiempos, en que las luces gozan de mayor extension, sean las mugeres mas instruidas; no podemos negarles que lo son en efecto; pero, cuantas dificultades, e inconvenientes para la eleccion de los libros propios de su enseñanza. Tal vez carecen de ellos ó son muy raros, al menos los proporcionados para facilitarlas el estudio de la literatura.

Con el vibo deseo de apartarlas de este notorio estorbo, hemos concebido el proiecto del presente Periodico, en el que se formará una coleccion de tratados metodicos y elementales, por donde las señoras puedan adquirirse los utiles conocimientos de las vellas letras, de la Logica, de la Moral, y de las buenas Artes, que tanto realzan el merito que mas las ennoblece.

No dudamos advertir aqui, que para esto nos valdremos de los escritores clasicos, á cuias excelentes obras unicamente falta su conformidad con el plan, que haora nos proponemos: es decir, el espurgarlas de los terminos tecnicos y facultativos, propios de la forma cientifica y escolastica. Aspiraremos al logro 
de que la Mythologia dege de ser un caso confuso donde la inaginacion se pierde; de que los preceptos, y reglas de la Grammatica de nuestro propio idioma se despegen de su aridez y sequedad; y de que desaparezca en las definiciones metalisicas de la Logica la obscuridad que las acompaña; por ultimo procuraremos salvár las vellas letras del grueso muro que las tiene separadas del delicado sexo. Si no lo consiguiesemos enteramente, á lo menos tal será el punto á que nos aproximaremos, y al cual se destinará el primer articulo de este Periodieo, reservandonos para el segundo las variedades morales, delincadas por diferentes rasgos de crudicion, con externsion á las noticiás de eronomia donnesucal de industria mugeril; de sus varias obras de humanidad para con los desvalidos, y necesitados; de los exercicios de devocion en las Cofradias, Hermandades, Hospitales, Colegios; y en fin de todos los Actos de conmiseracion y catidad de las señoras; por lo que roganos, con instancia, se nos hagan saver. euviando los avisos á cualduiera de las clos libreries del despacho de este nuestro papel. Tambien por el mismo publicaremos, si se nos remitiese algun fraymento litcrario, ó Anecdota agraclable, ya sea cn verso ó prosa, en forma de discurso ó carta, cono tengan amalogia con las costumbres, abusos, modas, recreos, inutilidades, virtudes, o defertus en general de las personas á quicnes dedicamos nuestro escrito; en el estilo no nos detendremos pues el jocoso, el serio, el familiar y el grave todos serán bien admitidos, con tal que guarden el decoro y moderacion de una discreta modestia, de que jamás nos separaremos.

Se suscribe Señora...

\section{N."1. 2." clase. Variedades. El nuevo Periodista á las Damas Españokus}

No sé si consiste en qpue por cxperiencia ver que sin noticia de las scrías bien circunstanciadas del editor, nunca se lea con gusto un periodico, o en que mi amor propio me esta punzando para cue able de mi mismo, pero lo cierto es gue he llegado a persuadirme que devo absolutamente, sino nombrame, retratarme, y ann alavarme (segun Jo autorizaria el modesto nlow do de pensar de nuestro siglo) á lo menos cscusarme con Vus. del arriesgado y atrevido cmpeño de constituirme su nuevo bocrates.

Con ese animo tenia yo formado un largo Prólogo, que devia preceder á esta obra; mas aunque le creia mely esarto y digno del ermoso sexo, para cuien se destiuaha, un raro escrupulo de que no ela muy veridico le destinó á las llamas. Ingeuuo por naturaleza, é incapaz de ficcion (me decia yo á mi misno) pucs que juzgo que la fuerza del destino me obliga al cargo honroso que oy adopto, j,como he de aparentar pretestos que desfiguren su unico motivo? En efecto, Seño- 
ras mias; no un vano capricho, un orgullo insano, ni mucho menos algun otro interesillo me pone á los pies de Vnss. con riesgo de que sus desaires me reduzcan á la lastimosa suerte en que vemos, y hemos visto á varios de los que más han envidiado sus obsequios. Voy en fin a confesar de plano. No atribuio sino al influxo de mi [...] mi arribo, feliz, ó desgraciado, á la soverana regencia deste savio Museo en que presido.

Yo naci en un lugarcillo corto de la sencilla Alcarria. De mi Aguela, ni de mi Madre nunca he oido que algun estraño sueño las presagiara el papel que se me reservaba en el teatro de este nundo; pero sí llegué á saver de ellas otra especie de vaticinio, cuia vordad queda aora comprovada. El caso fue este.

En una hemmita, medio arruinada, de aquel pueblo, tenian su rancho unos gitanos el dia mismo en que vi la luz primera. Como si mis agudos chillidos se dirigiesen á llamarlas, tres gitands se havian ya metido en el portal de mi antigua casa, donde mi Aguela y la Comadre estaban exerciendo conmigo aquellas piadosas funciones, con que se prolonga nuestra triste existencia. Con ocasion tan favorable, por un poco de tocino, un solo huevo, y un delantal de paja, apenas estaba envuclto el recien nacido quando tuvo que prestar su tierna mano para que le encajaran la buenaventura. La Clausula de ella que mas eco hizo, y retubo mi buená Aguela fue la de que devia ser yo algun dia ol savio regente de una escuela central, cuyo auditorio, por la maior parte, jamas anteriormente havria recivido otra instruccion, que la correspondiente para poder formar muchas frases sin sentido, y largas conversaciones sobre modas, sobre el ceremonial de vodas, de saraos o de visitas particulares, y sobre el esquisito gusto del trage de una viuda, en el dia mismo en que empieza á serlo. Tal fue el pronostico, que mal esplicado por los arezados oraculos, y peor entendido por quienes devian cuidar de mi educacion, se interpreto de un modo lisongero, para pue tne empeñaran quando menos en la ilustre carrera de las letras, persuadiéndose ciegamente á que me labrarian ellas un destino opulente y brillante, con trascendencia a mi familia entera, que por esta razon, sicmpre me ha tenido por el objcto más amado de sus mejores esperanzas. Si asta aora (ablando con verdad) no se han cumplido, tampoco deveremos estranarlo, pues que el premio no deve preceder al travajoso merito, y los succesos mios han de lundarse sobre este magisterio, que ciertos hombres grandes, interpretes del egipciaco anuncio, han entendido devia dedicarse á la hermosa micad del humano genero, mitad siempre calumniada (dijo sobre esto un savio profesor del caudaloso Jena, consultado por mi) porque se cree devil; y solamente devil porque no ha tenido la educacion que este, de justicia, se merece.

Antorizado pues con la lexitimidad de la mision que llevo expuesta, nadic 
me arguirá de temerario en esta empresa, tanta mas ardua que es arto savido, que asta aora ningumo de nuestros Periodistas ha intentado instruir á nuestras Damas, destinandoles á lo menos ciertos Capitulillos de sus lojas volantes. Con tal silencio asienten sus editores á la opinion mahometana que las niega racionalidad, y aun alma. Lo contrario nos demuestra la experiencia en diferentes individuos del ermoso sexo por todas las ngciones, donde cuidadosamente se. atiende a su instruceion; y sin salir de nuestro patrio suek tampoco nos faltan exemplos de admiracion en varios exemplos que citaria yo aqui con gusto si pudiese servir uni elugio á realzar sm inerito. Siendo esto cierto, como vanbicu que Vms. son las micas interesadas en su ilustracion pтopia, las insto y ruego, por su naior biem, á que no desechen las leccioncs que se las prepara en este ni Liceo, a pesar de las piadosas intenciones, con que la candidez de algunas buenas almas de mis compatricios, procurarán oponerse á que se fixen en él esas delicadas plantas. Ellos deven saver cuánta es su pórdida, si el talento de Vms. se cultiva: son los triunfantes oy, y no lo son por otra causa, mas que por la superioridad de su mejor educarion; asi scñoras mias no hay mas que creerme sobre ni palabra; dense Vmds. á la aplicacion constante de las letras, proporcionadas a su capacidad, y estado, como aqui se las promete, y ellas producirán en esos nobles y semsibles corazones, los deliciosos frutos con que recomperisan la pequeña fatiga que su adquisicion causa; mas aún de esta misma me propongo yo aorrarlas, conociendo que mi tiemo auditorio no se ha de entregar á un estudio. que favigue st espiritu, ni entontezce su ing ginacion. Fil agradar es of dever mas fuerte, que lo impuso la naturaleza, y yo sé que los ratos que destinara el sexo encan1ador á unas especulaciones aridas y austeras, los quitaria injustamente al tiempo y medios del cumplimiento de esta su obligacion primaria. Aun asi, insistinos en la necesidad de su instruccion sencilla: ella realza la felicidad nusma, que distribuie la nuger por la sociedad; por lo tanto devemos desearlas instruidas, y nos toca por lo misno el proporcionarlas los medios mas suaves.

ral es en suma el espiritu que presidirá en las alases de este liceo, donde no se perderán jamás de vista estos dos principios: 1. "Se facilitará en el por la claridad el estudio metódico de las vellas lotras y de la moral. 2." Sé acortará su furación por la brevedad, más uroporcionada al delicado sexo. No solamente deve procurarse el no fastidiarle, sino ni aun ocuparle con esceso. Por lo demás, el viempo hará ver, si mi estilo es digno de Vms.; pues aunque carezca de notas,

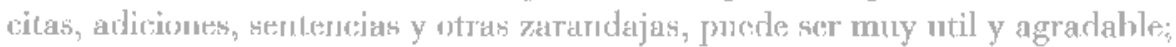
forque no solo el que danza por alto, hace ver que no es cojo, sino támbien el que anda con propiedad. Al mismo ticmpo las hará conocer, si la moralidad de: mi Gymmasio es austera, y ridicula, ó frivola y pesadi, hasta intentar cerrar las puertas de nuestros Coliseos, de los Saraos, tertulias y de otras varias diversio- 
nes que, con los correctibos y cautelas de la prudencia, son otras tantas caras de un recreo devido á los afanes miserables de nuestra triste vida; si acierto y adivino, cuando publique la significacion de las mutuas miradas de dos jovenes tiernos de diferente sexo, que en las numerosas concurrencias sin pronunciar una sola silaba se comunican y dicen cuanto quieren; si traen ó no consigo algunas consecuencias perjudiciales ó utiles esas modas nacidas en la rue de Saint Honoré de Paris, que desembarcan en nuestros pucrtos de la Montera y de las Carretas, y no paran su curso, hasta que convertidas en oro, buelven á su centro, burlandose de quien las ospedó mas generosamente; y por ultimo, el tiempo será el mejor testigo del exito dichoso ó infeliz de los humildes omenages que para la ilustracion de las Damas españolas ofrece, y presenta á S. P.

Su rendidissimo, humilissimo, y cordialissimo

Domine.

Noticias particulares de este Periódico

La semana anterior llebó la bolsa para el socorro del nuevo Hospital de las incurables la Excma. Sra.

En el General entró de semana la Sra. $D^{\mathrm{a}}$.

El dia tantos se celebraron las honras funebres de $\mathrm{D}^{\mathrm{a}}$. [ ...], muy acreedora al sentimiento general por su distinguido merito en tal ramo.

La Cofradia de t. celebrará funcion de iglesia solemne á su Sta. Patrona el dia $[\ldots]$ predicará el P. N...

La publicacion de los libros solamente que puedan ser utiles a las damas, 6 de que sean Autoras ellas mismas.

Las nuevas invenciones de industria mugeril.

La colocacion de las mugeres en alguna havilidad particular pero no de criadas, Nodrizas y Amas de llaves, \&cn.

N."2. 2. "clase, Variedades. Philantropia ó Humanidad

La presteza con que publico la siguiente relacion extractada fielmente de una carta que se me ha dirigido a este efecto, será la mejor prueva, para quien me la ha escrito de la deliciosa satisfaccion que me ha causado. 
«Lua joveru, soltera de las nias juteciosas eualidades viviendo en la unica compañia de su pobre nadre ve á esta que cae extenuada de devilidad por falta de alimento cae en un desmaio que la repitio por intervalos asta ures veces. El remedio estaba conocido por la triste hija; pero apurados tudos los arvitrios. a que recurre la extremada indigencia, se veia en la absoluta inposibilidad de poderle aplicar. Tremula, desconcertada y llorosa, corre hasta la calle para dirigirse a la casa de su Parroco. Atribuie ella al desorieu de sus potencias lo que devemos mirar oy ya como un efecto de la divina provideneiá, siempre atenta y vigilante para el socorro de lá virtud indigente. Equivoes lá avitacion, llanua a la pueria de la de una señora de un esterior noble, opulento, y sobre rodo afable, pues aperas echo la vista a la vernarsila, franqueo la entrada a la condolida soltera, fuien mucho mas consterrada, advirtiendo entonces su equivoracion, la dise: "Perdone: Vond. Sra. pues me crey llamar en el quiaro del Sr.

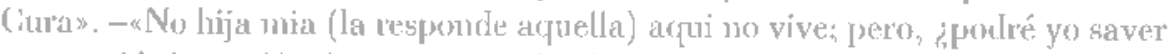
para qué le busca Vunt. con ese aire de afliceinn y tan aprosurada?". Redóblanse sus solloros, y axclama cou la voz docaida y penetrante de la candidez y ol do-

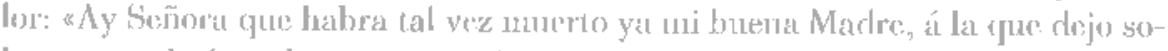

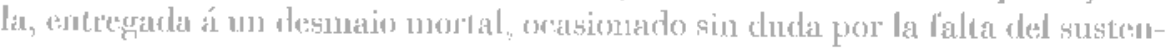

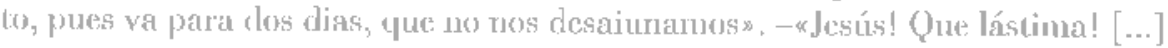
espore Voud. un corto instantes. Sice entre volando la dama a su avitacion y ne

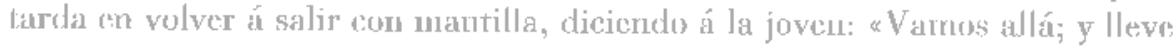

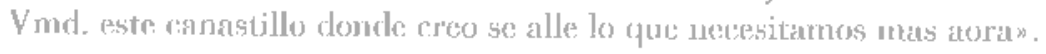

Ambas apresturar sus pasos. o mojor diriamos burlan con las alas, pue las

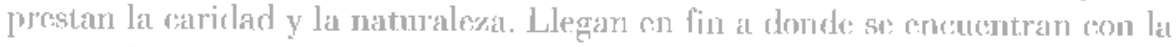
especie de cadaver tendido sobre un viejo gergori dando si ciertus señales de vida. pero arto equivoras, á lo meros para que las des deviles asistentes pudiesen procurarle su restablecimiento. Por fortuma un cirujane, avisado por la driacla de la Senora el cual las havia seguido sin perderlas de vista, entra, recurre al pulso y las alienta. «Nada lay aqui que temer ya (las dice). Lil mal es grande,

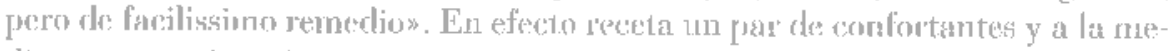

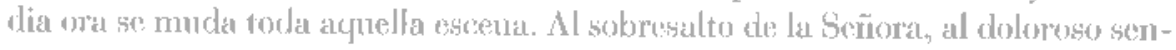

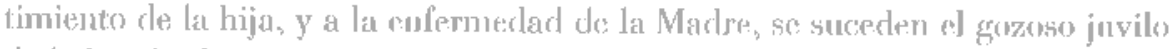
de la bienhechora, las alegres gracias de las favorecidas y los mutuos abrazos con que se desaogan aquellos ures corazones, gue no se han scparado todavia, in probablenente volvcrán á separarse, pues está ya formada la devornivacion por pl genio bicnhochor de la señora de no porderla numea de vista nuentras respire, para evitar otmo nuevo escollo que pueda hacer naufragar la virind ó la vida de estos clos seres numy acredoret jor su nacimiento y condueta á una suerte más dichosan. 
Apenas havia yo concluido la lectura de este acto de humanidad, cuando me asaltó un tropel de reflexiones, de las cuales verterá aqui algunas que tal vez podrán acarrear alguna utilidad.

Si el número de calamidades particulares es disminuido en esta Capital, to devemos sin duda á una multitud de almas celestiales que se ocultan cuidadosamente para hacer el bien. El vicio, la locura del lujo, y el orgullo se manifiestan á las claras, y como en triunfo, pero la tierua commiseracion, la generosidad y la virtud se esconden para servir á la humanidad en silencio, y sin ostenlacion, satisfechas unicamente con la vista del Ser Eterno. En efecto, sin la activa caridad que mutiplica los ausilios, que va á llebar remedio á los desvanes; que sorprende al pobre sobre su gergón; le consuela, le asiste, y le fortifica, haciendole ver que no está olvidado de todo el universo en su solitario infortunio, no solamente se allarían cadaveres, mucrtos de necesidad, y las guardillas de las casas scrvirian de sepulcro á la indigencia, sino que los delitos serían tambicn mucho mas frecuentes.

Una gran parte de la publica tranquilidad se deve á varios corazones sensibles, los cuales mientras la ley castiga como deve á los crimenes, ellos les sofocan en su nacimiento, por tanto son muy acreedores al onor universal, y devemos rendirles el respeto que se merecen.

Yo he creido contribuir á una parte de esta veneracion que se les deve, publicando en este Periodico todas las obras de caridad de que sea noticioso y me sean comunicadas, ya sea por el que las practicó (nombrandose ó con el velo anonimo) ya por las mismas personas con quienes se ham egecutado. Seguro de la fuerza del buen cxemplo no dudo de que la notoriedad de cada una de cllas producirá otras varias. Ni hay que preocuparse persuadiendose á que se atribuirá a vanidad, si se hace asi. Verdad es que la vanagloria corrompe cl precioso merito de las buenas acciones, pero no lo es menos, el que todos estanos obligados á excitar á ellas por nuestro exemplo. Además, esta tambien muy visto, que en otras naciones, donde las publican los Periodicos, no solo se nota diariamente su multiplicacion, sino que se evitau las injustas quejas del Pobre contra la pretendida insensivilidad del Poderoso: motivos por que ruego con instancia se me avise de ellas». 